\title{
Estimating Daily Actual Evapotranspiration at a Landsat-Like Scale Utilizing Simulated and Remote Sensing Surface Temperature
}

\author{
Dakang Wang ${ }^{1,2}$, Tao $\mathrm{Yu}^{1}$, Yan Liu ${ }^{1}$, Xingfa Gu ${ }^{1,2}{ }^{2}$, Xiaofei Mi ${ }^{1}$, Shuaiyi Shi ${ }^{1}{ }^{1}$, Meihong Ma ${ }^{3}$, Xinran Chen ${ }^{1,2}$, \\ Yin Zhang ${ }^{1,2}$, Qixin Liu ${ }^{1,2}$, Faisal Mumtaz ${ }^{1,2}$ and Yulin Zhan ${ }^{1, *(D)}$ \\ 1 Aerospace Information Research Institute, Chinese Academy of Sciences, Beijing 100094, China; \\ wangdk@aircas.ac.cn (D.W.); yutao@radi.ac.cn (T.Y.); liuyan@aircas.ac.cn (Y.L.); guxf@radi.ac.cn (X.G.); \\ mixf@aircas.ac.cn (X.M.); shisy01@radi.ac.cn (S.S.); chenxr@aircas.ac.cn (X.C.); zhangyin@radi.ac.cn (Y.Z.); \\ liuqx@radi.ac.cn (Q.L.); faisal@aircas.ac.cn (F.M.) \\ 2 University of Chinese Academy of Sciences, Beijing 100094, China \\ 3 School of Geographic and Environmental Sciences, Tianjin Normal University, Tianjin 300387, China; \\ mamh@tjnu.edu.cn \\ * Correspondence: zhanyl@radi.ac.cn
}

\section{check for} updates

Citation: Wang, D.; Yu, T.; Liu, Y.; Gu, X.; Mi, X.; Shi, S.; Ma, M.; Chen,

X.; Zhang, Y.; Liu, Q.; et al. Estimating Daily Actual Evapotranspiration at a Landsat-Like Scale Utilizing Simulated and Remote Sensing Surface Temperature. Remote Sens. 2021, 13, 225. https://doi.org/ $10.3390 /$ rs 13020225

Received: 22 November 2020 Accepted: 8 January 2021 Published: 11 January 2021

Publisher's Note: MDPI stays neutral with regard to jurisdictional clai$\mathrm{ms}$ in published maps and institutional affiliations.

Copyright: (C) 2021 by the authors. Licensee MDPI, Basel, Switzerland. This article is an open access article distributed under the terms and conditions of the Creative Commons Attribution (CC BY) license (https:// creativecommons.org/licenses/by/ $4.0 /)$.

\begin{abstract}
Actual evapotranspiration (ET) with high spatiotemporal resolution is very important for the research on agricultural water resource management and the water cycle processes, and it is helpful to realize precision agriculture and smart agriculture, and provides critical references for agricultural layout planning. Due to the impact of the clouds, weather environment, and the orbital period of optical satellite, there are difficulties in providing daily remote sensing data that are not contaminated by clouds for estimating daily ET with high spatial-temporal resolution. By improving the enhanced spatial and temporal adaptive reflectance fusion model (ESTARFM), this manuscript proposes the method to fuse high temporal and low spatial resolution Weather Research and Forecasting (WRF) model surface skin temperature (TSK) with the low temporal and high spatial resolution remote sensing surface temperature for obtaining high spatiotemporal resolution daily surface temperature to be used in the estimation of the high spatial resolution daily ET (ET_WRF $\mathrm{HR}_{\text {HR }}$. The distinction of this study from the previous literatures can be summarized as the novel application of the fusion of WRF-simulated TSK and remote sensing surface temperature, giving full play to the availability of model surface skin temperature data at any time and region, making up for the shortcomings of the remote sensing data, and combining the high spatial resolution of remote sensing data to obtain ET with high spatial (Landsat-like scale) and temporal (daily) resolution. The ET_WRF $F_{H R}$ were cross-validated and quantitatively verified with MODIS ET products (MOD16) and observations (ET_Obs) from eddy covariance system. Results showed that ET_WRFHR not only better reflects the difference and dynamic evolution process of ET for different land types but also better identifies the details of various fine geographical objects. It also represented a high correlation with the ET_Obs by the $R^{2}$ amount reaching 0.9186. Besides, the RMSE and BIAS between ET_WRF HR and the ET_Obs are obtained as $0.77 \mathrm{~mm} / \mathrm{d}$ and $-0.08 \mathrm{~mm} / \mathrm{d}$ respectively. High $\mathrm{R}^{2}$, as well as the small RMSE and BIAS amounts, indicate that ET_WRF $\mathrm{HR}_{\mathrm{R}}$ has achieved a very good performance.
\end{abstract}

Keywords: evapotranspiration; WRF; surface temperature; fusion; high spatiotemporal resolution; water resource management

\section{Introduction}

Estimation of actual evapotranspiration (ET) with high spatiotemporal resolution not only conduces to the macro-control of water resources and the research of water cycle process, but also helps to realize precision agriculture and smart agriculture, and provides important references for urban and agricultural layout planning [1-3]. In the long-term 
and stable monitoring environment of meteorological stations, as long as the instruments do not fail, the long-term series of ET based on a single site is usually easy to achieve. Very high temporal resolution and relatively accurate results can be obtained by the advantage of traditional methods to calculate ET [4-8]. Remote sensing data makes the estimation of regional ET more efficient and convenient compared with the site data [9-11]. Surface energy balance system (SEBS) model based on remote sensing technology has been widely used in recent years to estimate ET at different time and space scales [12-16]. By ignoring the water demand for the organisms and the effect of near-surface advection, the latent heat flux is estimated as the residual of the energy balance equation $[17,18]$. The calculation of sensible heat flux based on the difference between surface temperature and air temperature is the core of SEBS model [19-21]. Using satellite-borne thermal imaging sensors to record the thermal infrared information of ground features for retrieval of surface temperature has become an effective method for dynamically monitoring spatial distribution of surface temperature in a large area [22-25], making up for the inadequacy of traditional monitoring methods in obtaining regional surface temperature [26]. However, due to their vulnerability to clouds, weather environment (such as cloudy, haze, or sandstorm) and revisit cycles, most optical remote sensing satellites cannot provide continuous daily high-quality monitoring data in any area, which makes it a difficulty to obtain continuous daily high-resolution ET using remote sensing data from only a single source [27].

Effective fusion algorithms [28-32] or temporal upscaling and reconstruction methods [33-39] have been used to construct continuous time-series of surface temperature based on remote sensing data for the calculation of ET. Some high temporal resolution ET products are released for such purpose, such as MODIS ET product (MOD16A2) with a temporal resolution of 8 days and a spatial resolution of $500 \mathrm{~m}$ [37]; ETWatch products, published by Heihe Plan Data Management Center (HPDMC), with monthly temporal resolution and $1 \mathrm{~km}$ spatial resolution [38]; ETMonitor products, published by HPDMC, with a temporal resolution of 8 days and a spatial resolution of $250 \mathrm{~m} \mathrm{[40];} \mathrm{Daily} \mathrm{ET}$ Datasets (2012), published by HPDMC, with daily temporal resolution and $1 \mathrm{~km}$ spatial resolution. Although these achieved good results, the spatial resolution of these products does not exceed $100 \mathrm{~m}$, and not many temporal resolutions can reach continuous daily intervals [31,35,41,42].

An important difficulty in using SEBS model to estimate daily ET with high spatialtemporal resolution is to provide daily surface temperature with high spatial-temporal resolution. With this original intention, we tried to develop a scheme to achieve continuous daily high spatiotemporal resolution ET through the fusion of surface skin temperature (TSK) simulated by Weather Research and Forecasting (WRF) model and remote sensing land surface temperature (LST) retrieved from Landsat thermal infrared band. Wang et al. [43] have offered an NDVI-based ET correction method which forms a complete scheme for estimating reliable daily ET based on SEBS using daily TSK. On this basis, this paper will further explore a feasible scheme to estimate higher spatial-temporal daily actual ET. The ESTARFM data fusion algorithm is improved by adding a normalization module that is adapted to obtain daily surface temperature data with high spatiotemporal resolution. For such purpose, TSK with high time resolution and low spatial resolution from WRF and LST with low time resolution and high spatial resolution from Landsat satellite images were merged, giving full play to the advantages of the high temporal resolution of the model surface skin temperature and the high spatial resolution of Landsat surface temperature to realize the reliable estimation of continuous high spatial (Landsatlike scale) and temporal (daily) resolution ET during the growth season (May 1-September 29) over Zhangye Oasis in 2015. It should be noted that this research is regarded as an in-depth extension of Wang et al. [43], therefore, the study area and WRF model experiment design are the same as in Wang et al. [43], from which the difference is that this research will provide a scheme to obtain higher spatial-temporal resolution daily ET. 


\section{Materials and Methods}

\subsection{Description of the Study Area}

The Heihe River Basin (HRB) is located in the middle of the Hexi Corridor in the arid and semi-arid regions of northwest China. It is about $390 \mathrm{~km}$ wide from east to west and 510 $\mathrm{km}$ long from north to south. It covers an area of approximately $143,000 \mathrm{~km}^{2}$, which is the second-largest inland river basin in China (Figure 1, left) [44]. With a total length of $928 \mathrm{~km}$, the mainstream receives snowmelt supply from Qilian Mountain in the south and moistens the vast area of Ejina Banner in the north. Zhangye Oasis area $(46 \mathrm{~km} \times 46 \mathrm{~km})$, shown in the right panel of Figure 1, is the study area, which is located in the HRB midstream where the desert-oasis landscape exists. The predominant crops in this region are mainly wheat and maize [31]. The annual average temperature, rainfall, and evaporation potentials for the study area are $7.5^{\circ} \mathrm{C}, 136.8 \mathrm{~mm}$, and $1840.1 \mathrm{~mm}$ respectively [45].

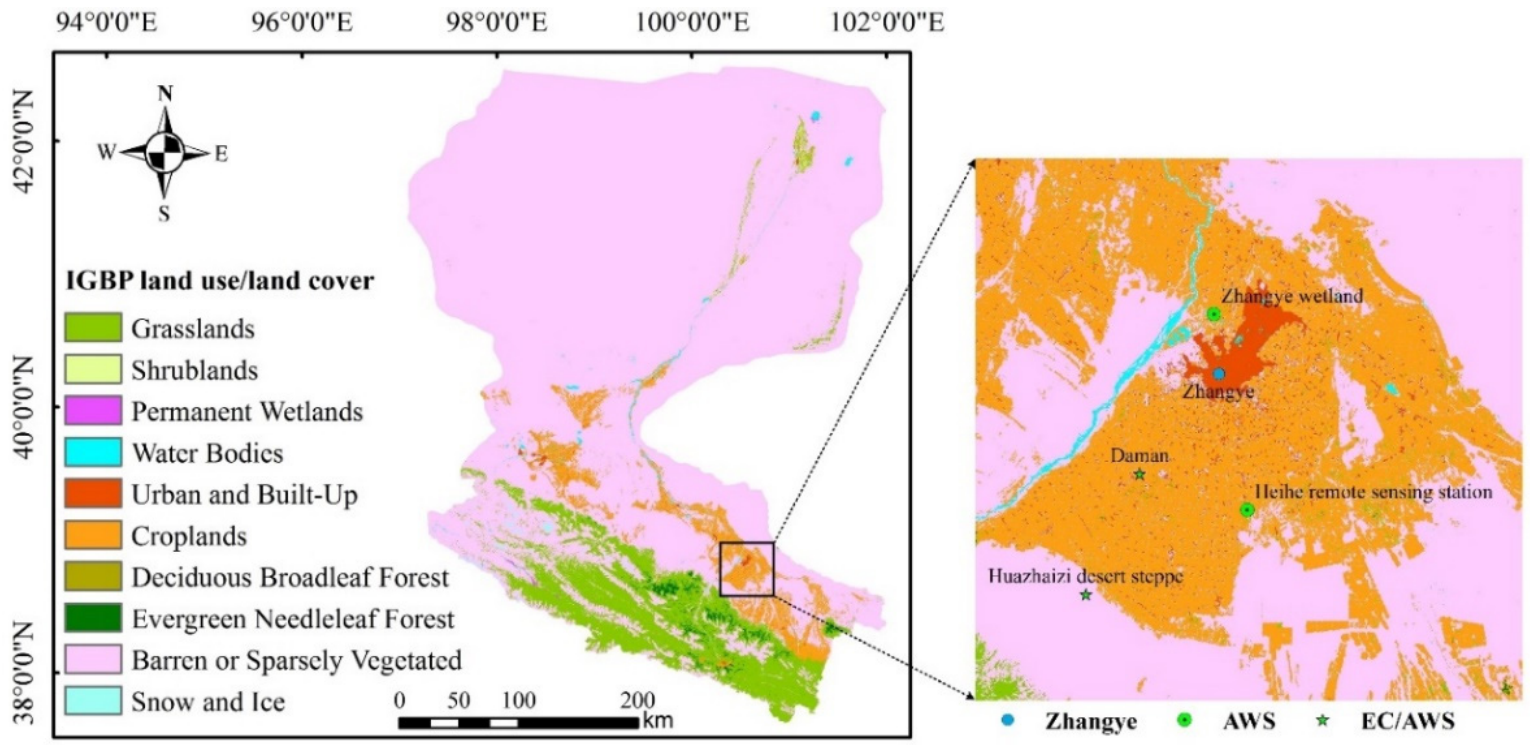

Figure 1. The Heihe River Basin (left) and the study area (right) [43].

\subsection{Data}

\subsubsection{Ground Measurements}

Meteorological variables including wind speed, air temperature, relative humidity, air pressure, and solar net radiation are required for the estimation of daily ET, and $2 \mathrm{~cm}$ soil temperature $\left(T_{S}\right)$ is used for surface temperature validation. The observations are collected from four automatic weather stations (AWS) (Figure 1), which were established in the midstream of HRB during the Heihe Watershed Allied Telemetry Experimental Research (HiWATER) program conducted in 2015 [46]. The underlying surface and the geographic information of the sites are summarized in Table 1.

Table 1. The underlying surface and geographic information of the four sites in Zhangye Oasis.

\begin{tabular}{cccccc}
\hline Station & Land Cover & Longitude (E) & Latitude (N) & Elevation (m) & Instrument \\
\hline Daman & Cropland & 100.3722 & 38.8555 & 1556 & AWS, EC \\
Heihe remote sensing station & Grassland & 100.4756 & 38.827 & 1560 & AWS \\
Huazhaizi desert steppe & Barren land & 100.3186 & 38.7652 & 1731 & AWS, EC \\
Zhangye wetland & Wetland & 100.4464 & 38.9751 & 1460 & AWS \\
\hline
\end{tabular}

Each AWS is equipped with sensors to collect meteorological data with 10-min intervals, among which, Daman and Huazhaizi Desert stations are additionally equipped with an eddy covariance system (EC) to collect data every $30 \mathrm{~min}$. Meteorological data 
covering 1 May-29 September 2015, as the study period, were downloaded from Heihe Plan Data Management Center (HPDMC, http:/ / www.heihedata.org/). Due to instrument failure, meteorological data at Huazhaizi Desert station was only available from 11 June to 29 September 2015. The meteorological data closest to the revisit time of MODIS satellite (10:00-12:00) is considered for interpolation using Inverse Distance Weighting (IDW) method by taking the elevation into consideration.

\subsubsection{Satellite Data}

A total of 16 Landsat images (including Landsat7 and Landsat8) with no or a small portion of clouds during the growing season of Zhangye Oasis were screened out to retrieve high spatial resolution NDVI and LST data. The Neighborhood similar pixel interpolator (NSPI) algorithm [47] was used to fill the Landsat7 ETM+ image strips which were caused by the failure of scan line corrector (SLC) onboard Landsat7 satellite on 31 May 2003 [48], and then the modified NSPI algorithm [49] was adopted to remove the clouds in the Landsat7 ETM+ image and Landsat8 OLI image. The radiation transmission method [50] was used to retrieve LST, and then the retrieved LST was downscaled with the cubic convolution method to obtain the $30 \mathrm{~m}$ LST. The $30 \mathrm{~m}$ LST would then be used as one of the preparation data for reconstruction of continuous daily surface temperature by fusing with WRF TSK extracted at the same or the closest time of the Landsat satellite revisit. The MOD09A1 reflectance product with a time resolution of 8 days during the growing season is used to retrieve time-series of NDVI with a spatial resolution of $500 \mathrm{~m}$. The $30 \mathrm{~m}$ and $500 \mathrm{~m}$ NDVI are used to obtain NDVI with an interval of 8 days and spatial resolution of $30 \mathrm{~m}$ based on the Enhanced Spatial and Temporal Adaptive Reflectance Fusion Model (ESTARFM), and $30 \mathrm{~m}$ Digital Elevation Model (DEM) data from ASTER GDEM V2 is used to provide terrain information. The satellite data specifications used in the study are listed in Table 2.

Table 2. Satellite image specifications used for the study for the year 2015.

\begin{tabular}{cccc}
\hline Satellite Images & Temporal Resolution & Spatial Resolution & Day of Year (DOY) \\
\hline Landsat7 ETM+ & - & $30 \mathrm{~m}$ & $104,136,184,200,216,232,248,280$ \\
Landsat8 OLI & - & $30 \mathrm{~m}$ & $112,144,176,208,240,256,272,288$ \\
MOD09A1 & 8 days & $500 \mathrm{~m}$ & $105-289$ \\
DEM & - & $30 \mathrm{~m}$ & - \\
\hline
\end{tabular}

\subsubsection{Surface Skin Temperature}

The hourly TSK simulated by the WRF model during the growing season of Zhangye oasis was adopted for the study. The resolution of the land surface information elements of the WRF model is too coarse, data generation time is too old to accurately describe the current surface characteristics, and data accuracy are not high in China. For this reason, the land surface information elements of WRF model including soil type, soil hydraulic properties table, land cover type, terrain height, leaf area index, surface albedo, and annual maximum snow albedo are updated and improved as the first step before performing the WRF simulation experiments. The TSK closest to the revisit time of the Landsat satellite is extracted for the fusion process with the Landsat surface temperature.

\subsection{WRF Model Experiments}

WRFv3.9.1 is utilized for the three nested domains namely D01, D02, and D03 with horizontal grid spacing of $25 \mathrm{~km}, 5 \mathrm{~km}$, and $1 \mathrm{~km}$ respectively (Figure 2). The outermost mesh for D01 is slightly larger than the HRB with center longitude and latitude of $100^{\circ} \mathrm{E}$ and $40^{\circ} \mathrm{N}$ respectively, while D02 is smaller than the HRB. D03 represents the Zhangye oasis area, the study area of this research. The simulation period is selected as 1 May-30 September 2015. The model output results are set hourly while the spin-up time for the 
first $48 \mathrm{~h}$ to stabilize the model. Table 3 summarizes the WRF configuration and physical parameterization for the study area.

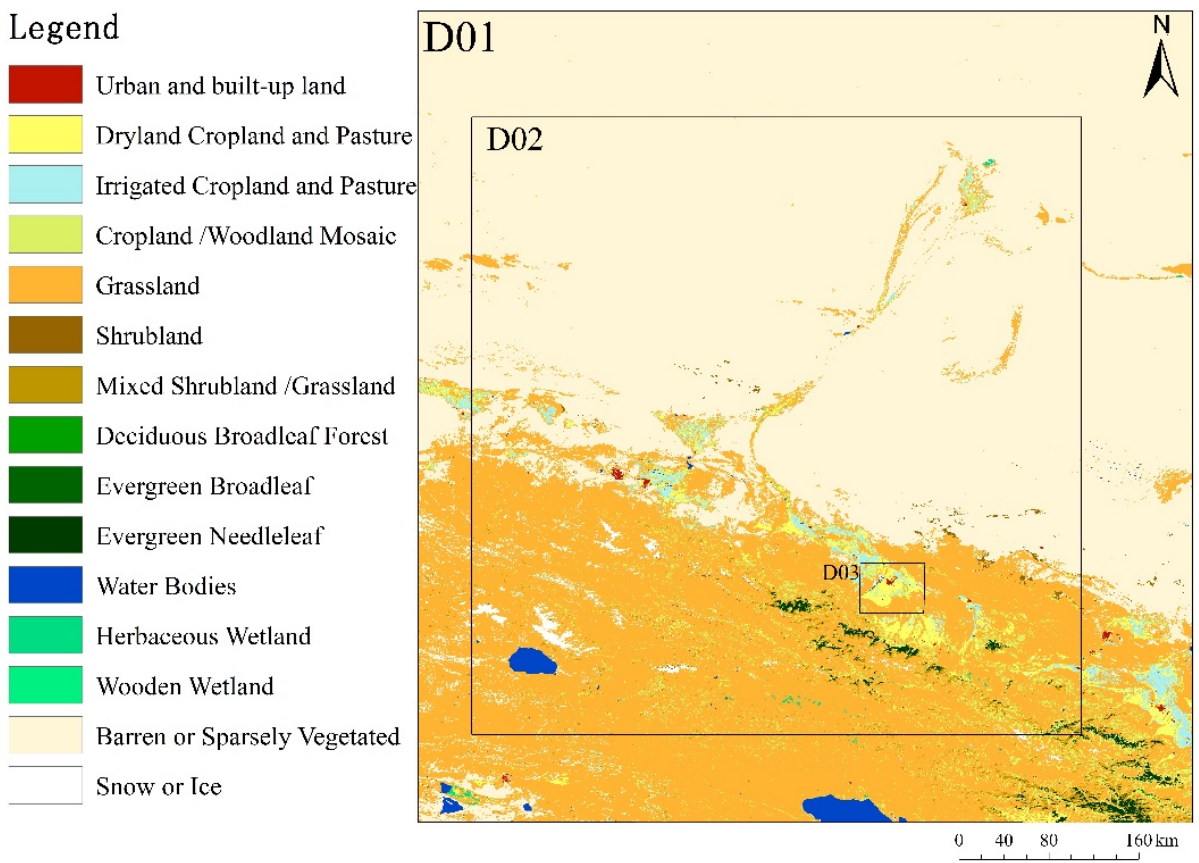

Figure 2. Three nested domains displayed on a 2015 Global Land Cover map, which has been reclassified and integrated according to the United States Geological Survey (USGS) classification system [43].

Table 3. WRF configuration and physical parameterization for the study area.

\begin{tabular}{cccc}
\hline Configuration & D01 $\mathbf{( 2 5} \mathbf{~ k m )}$ & D02 (5 km) & D03 (1 km) \\
\hline Horizontal grids & $46 \times 58$ & $141 \times 151$ & $46 \times 46$ \\
Integration time (s) & 150 & 30 & 6 \\
Microphysics & Kessler & Kessler & Kessler \\
Cunulus & Kain-Fritsch & Kain-Fritsch & Kain-Fritsch \\
Planetary boundary layer & MYJ & MYJ & MYJ \\
Short-wave radiation & Dudhia & Dudhia & Dudhia \\
Long-wave radiation & RRTM & RRTM & RRTM \\
Land surface & Noah LSM & Noah LSM & Noah LSM \\
Surface layer & Monin-Obukhov & Monin-Obukhov & Monin-Obukhov \\
Initial boundary condition & NCEP/FNL & D01 & D02
\end{tabular}

\subsection{Modifications to ESTARFM Fusion Algorithm}

ESTARFM is an algorithm for the reconstruction of high spatial and temporal resolution data under various surface conditions including uniform and non-uniform surface [51], which is considered for the fusion of high temporal and low spatial resolution MODIS reflectance with low temporal and high spatial resolution Landsat reflectance to benefit from the advantage of high temporal resolution MODIS and high spatial resolution Landsat data [51-53].

This manuscript improved ESTARFM algorithm by adding a normalization module to obtain the daily surface temperature with high spatiotemporal resolution; water bodies and wetland are excluded when performing normalization. One of the key processes is to fuse TSK with high temporal and low spatial resolution with Landsat surface temperature with low temporal and high spatial resolution, and the fusion results are then normalized based on TSK to obtain surface temperature with high spatiotemporal resolution. TSK and 
Landsat surface temperatures should be resampled to the same resolution and coordinate system before running ESTARFM. The assumptions are considered to be satisfied as the surface temperature change rate $a$ can be thought as stable and the surface temperature linearly changes from $t_{m}$ to $t_{n}$ during a short time period [51].

WRF TSK needs to be pre-processed before the execution of the algorithm to ensure that the prepared data for model operation have the same dimensions as Landsat LST. The lines and the samples keep the same and the bilinear interpolation method is selected for resampling to reduce the impact of geographic reference errors. The process of acquiring surface temperature with the high spatiotemporal resolution is provided in Figure 3. The first step is to screen out the similar pixels as the one in the center of the window based on the provided Landsat surface temperature data at date $t_{m}$ and $t_{n}$. The second step is to input the TSK of $t_{m}$ and $t_{n}$ which has been resampled to the same spatial resolution and coordinate system as Landsat surface temperature to calculate the similar pixel weight. In the third step, the conversion coefficient between Landsat surface temperature and WRF TSK is solved by the weighted least square method. The fourth step is to provide the WRF TSK at date $t_{p}$ to output the fusion result with the same spatial resolution as $t_{p}$ Landsat surface temperature. Finally, based on re-sampled WRF TSK, the Equation (1) is used to normalize the fusion results obtained in the fourth step according to different types of underlying surfaces to retrieve high-resolution surface temperature data.

$$
F_{j}=F_{(D O Y, j)}-\frac{\sum_{1}^{N}\left(F_{(i, j)}-W_{(i, j)}\right)}{N}
$$

where $F_{j}$ is the surface temperature of the No.j land cover type after normalization; $F_{(D O Y, j)}$ is the surface temperature of the No. $j$ land cover type that came from the fusion of TSK and the surface temperature retrieved by remote sensing; $F_{(i, j)}$ is the No.i pixel value of $F_{(D O Y, j)} ; W_{(i, j)}$ is the No.i pixel value in the No.j land cover type after the TSK is resampled to the same resolution as the remote sensing surface temperature; $N$ is the total number of pixels of the No.j land cover type.

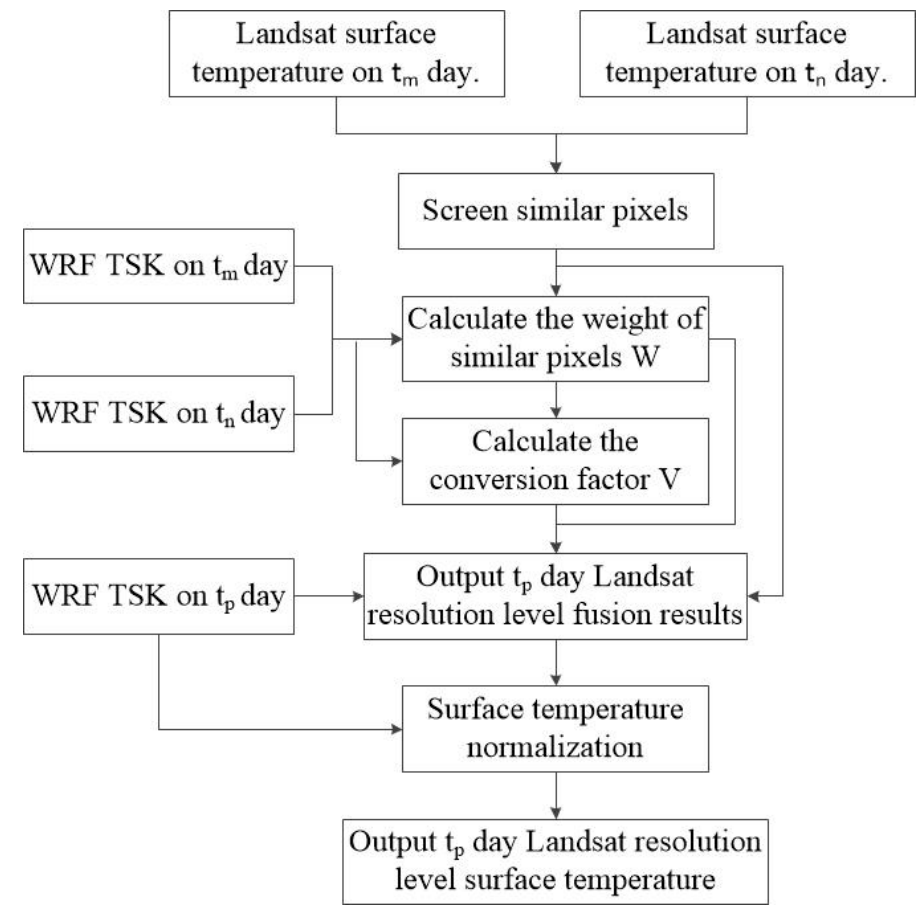

Figure 3. Process of obtaining surface temperature with high spatiotemporal resolution.

The relevant parameters are set accordingly while the model is executed. For instance, the half-width of the window is set to 25 so the actual size of the window is $25 \times 2+1=51$ 
pixels according to the land cover data provided by HPDMC. The total categories number of terminal pixels is set to 7 to improve the calculation speed. Lastly, the maximum number of similar pixels to be screened out is set to 20 . The image is cropped into blocks with the row and column size of $500 \times 500$ and then the calculation is performed.

\subsection{ET Estimation Scheme for High Spatiotemporal Surface Temperature}

Remote sensing surface temperature is an important input of the SEBS model for estimating ET. It has been declared in Wang et al. [43] that ET obtained by using WRF TSK to directly replace remote sensing surface temperature input SEBS model is generally high in the whole area. Furthermore, the NDVI correction method is proposed to estimate reliable ET, which is also adopted in this research. To achieve daily ET with high spatialtemporal resolution, ET is estimated as the first step based on the SEBS model by using the surface temperature with high spatiotemporal resolution obtained by the fusion algorithm. Then, multiply the ET obtained in the first step by NDVI, i.e., Equation (7) in Wang et al. [43], while the correction target does not include the water area.

The key of SEBS model is to use the difference between the surface and air temperature to calculate the sensible heat flux through iteration (see Equation (2)), and then calculate the daily actual ET (see Equation (4)) according to the energy balance residual (see Equation (3)). The details about the algorithm process of the SEBS model in the estimation of the ET are referred to $\mathrm{Su}[17]$.

$$
\begin{gathered}
H=\frac{\rho C_{p}\left(T_{s}-T_{a}\right)}{r_{a h}} \\
\lambda E_{\text {daily }}=R_{n}-G_{0}-H \\
E_{\text {daily }}=8.64 \times 10^{7} \times \Lambda_{0}^{24} \times \frac{R_{n}-G_{0}}{\lambda \rho_{w}}
\end{gathered}
$$

where $R_{n}$ is the net radiation; $G_{0}$ is the soil heat flux; $H$ is the turbulent sensible heat flux; $\lambda E_{\text {daily }}$ is the turbulent latent heat flux; $\lambda$ is the latent heat of the vaporization and $E_{\text {daily }}$ is the daily actual ET; $\rho$ is air density; $C_{p}$ is air specific heat; $r_{a h}$ is the aerodynamic resistance to heat transport; $T_{S}$ is the surface temperature; $T_{a}$ is the air temperature near the surface at a reference height of $2 \mathrm{~m} ; \Lambda_{0}^{24}$ is the daily evaporative fraction; $\rho_{w}$ is the density of water.

\subsection{Evaluation Method}

The statistical indicators including the Root Mean Square Error (RMSE), the bias (BIAS), and the coefficient of determination $\left(R^{2}\right)$ are adopted to evaluate the accuracy of the simulation including WRF TSK and estimated ET as the calculation formulas as follows [54]:

$$
\begin{gathered}
\text { RMSE }=\sqrt{\frac{\sum_{i=1}^{n}\left(S_{i}-O_{i}\right)^{2}}{n}} \\
\text { BIAS }=\frac{\sum_{i=1}^{n}\left(S_{i}-O_{i}\right)}{n} \\
R^{2}=\frac{\left[\sum_{i=1}^{n}\left(S_{i}-\bar{S}\right)\left(O_{i}-\bar{O}\right)\right]^{2}}{\sum_{i=1}^{n}\left(S_{i}-\bar{S}\right)^{2} \sum_{i=1}^{n}\left(O_{i}-\bar{O}\right)^{2}}
\end{gathered}
$$

where $S_{i}$ is No. $i$ day simulation and $O_{i}$ is No. $i$ day measurement. $\bar{S}$ and $\bar{O}$ represents the mean of simulations and measurements respectively while $n$ is the number of days.

\section{Results}

\subsection{Evaluation of High Spatiotemporal Resolution Surface Temperature}

Both Sohrabinia et al. [55] and Wang et al. [43] used $2 \mathrm{~cm}$ soil temperature $\left(\mathrm{T}_{\mathrm{S}}\right)$ to verify WRF TSK. $T_{S}$ was also used to evaluate the surface temperature with high spatial and temporal resolution obtained by fusion $\left(\mathrm{TSK}_{\mathrm{f}}\right)$ in this research. Verification results in Figure 4 show that $\mathrm{TSK}_{\mathrm{f}}$ have good correlation with $\mathrm{T}_{\mathrm{s}}$ at each site. $R^{2}$ is obtained to be 0.6467 , 
0.7102 and 0.7613 respectively. RMSE and BIAS between $\mathrm{TSK}_{\mathrm{f}}$ and $\mathrm{T}_{\mathrm{s}}$ at Daman are the smallest, being $2.26{ }^{\circ} \mathrm{C}$ and $-0.34{ }^{\circ} \mathrm{C}$, respectively. Dynamic evolution trend and correlation (Figure 5) between WRF TSK (before fusion) and $\mathrm{T}_{\mathrm{S}}$ was compared to infer the possible reason for high RMSE found at Heihe Remote Sensing Station and Huazhaizi. Results show that the BIAS of WRF TSK at Heihe Remote Sensing Station and Huazhaizi Station are both negative, and have high RMSE, indicating that WRF TSK is generally lower than $\mathrm{T}_{\mathrm{S}}$, which may lead to high RMSE of the TSK . The surface skin temperature (TSK) is simulated by Noah Land Surface Model (LSM) in WRF model, in which soil and vegetation are regarded as a whole [56], therefore, the simulation of TSK in vegetation and non-vegetation areas may show different accuracy. Accurate land heterogeneity will conduct reliable and accurate numerical modeling $[57,58]$, improving the accuracy, timeliness and spatial resolution of parameters (such as soil texture, soil water content, and soil hydrological parameter tables) related to TSK simulation in the Noah LSM and is one of the important ways to enhance the accuracy of WRF TSK. Moreover, mathematical fitting methods or bias correction can be used to calibrate the simulated data (including WRF TSK and Landsat LST) is an efficient means to improve the accuracy of the TSK . The BIAS between TSK and $\mathrm{T}_{\mathrm{S}}$ at the three sites are all less than zero, which also indicates that $\mathrm{TSK}_{\mathrm{f}}$ is generally lower than $\mathrm{T}_{\mathrm{s}}$ at the three sites. Comparison with the observations shows that $\mathrm{TSK}_{\mathrm{f}}$ have achieved a good fusion effect, greatly improved the spatial resolution of the WRF TSK, and will be used for the estimation of daily ET with high spatiotemporal resolution.

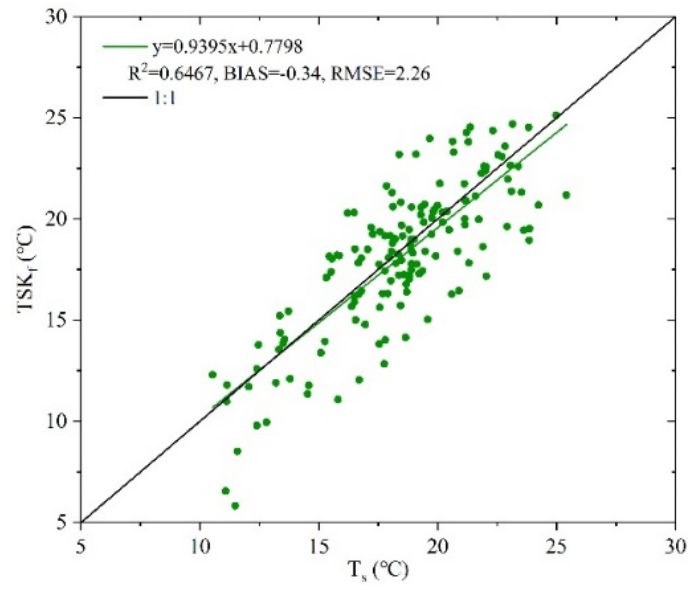

(a)

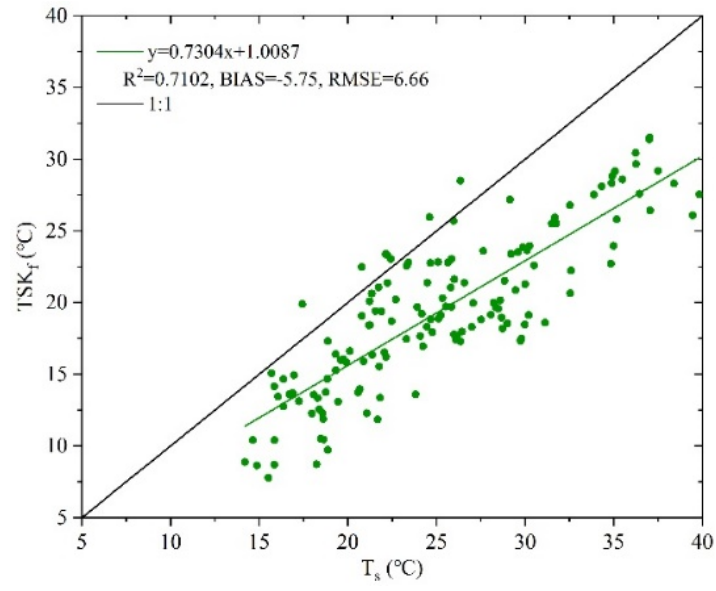

(b)

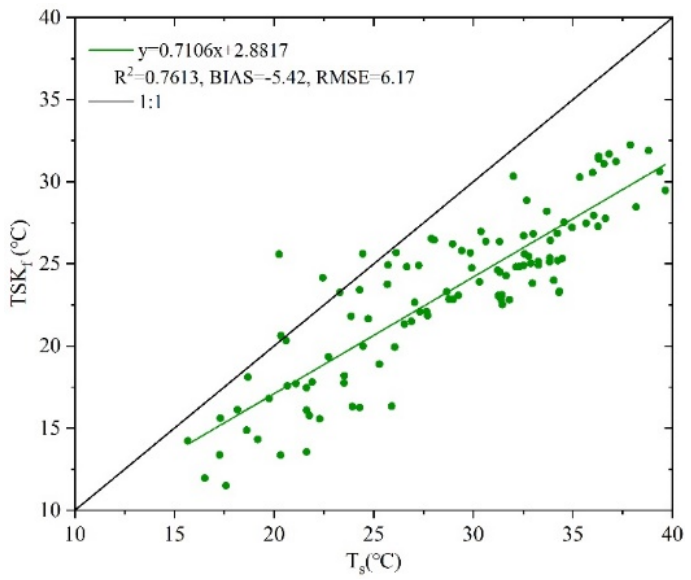

(c)

Figure 4. Scatter diagram of the high spatiotemporal resolution surface temperature $\left(\mathrm{TSK}_{\mathrm{f}}\right)$ and measured $\mathrm{T}_{\mathrm{s}}$ : (a) Daman; (b) Heihe remote sensing station; (c) Huazhaizi. 


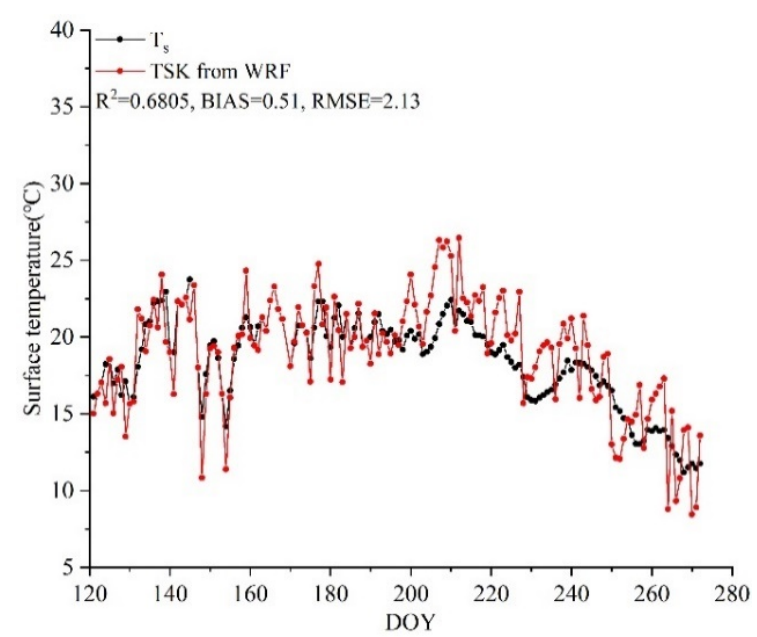

(a)

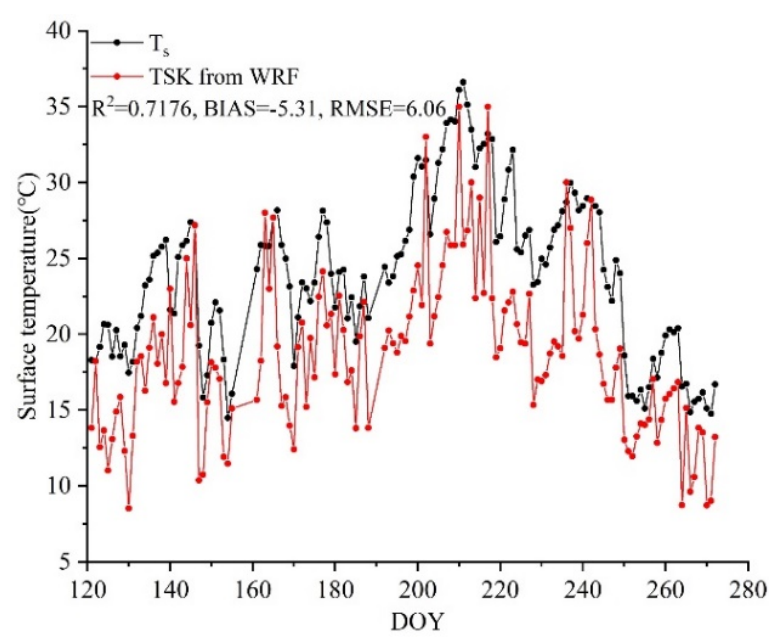

(b)

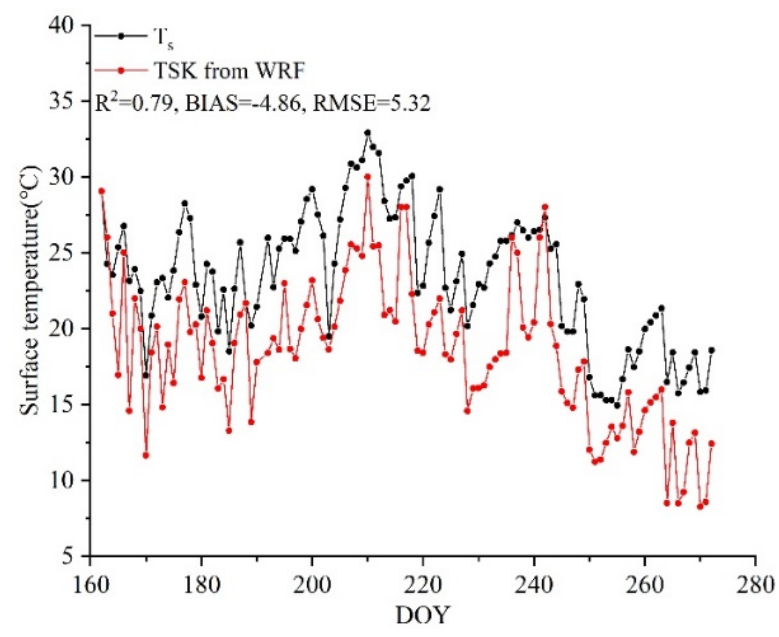

(c)

Figure 5. Correlation between WRF TSK (before fusion) and $\mathrm{T}_{\mathrm{S}}$ and dynamic evolution trend: (a) Daman; (b) Heihe remote sensing station; (c) Huazhaizi.

\subsection{Spatial Variation of High Spatiotemporal ET}

Figure 6 gives out spatial variation of high spatiotemporal ET throughout the whole growing season, and the water bodies maintain a higher ET. The bare land exhibits lower ET amounts and the farmlands present significant changes over time. Since the period was still in the stage of crop planting in early May, the farmland as a whole represented a lower ET and then increased relatively by the end of May. As the growth of crops and the gradual increase of temperature, ET of farmland increased significantly in June and formed a strong contrast with the lower ET for the bare land regions. ET is generally higher in July and August when the vegetation grows vigorously. It reaches the maximum at the end of July and early August and then begins to decline as the crops gradually mature to the end of August. ET began to decrease significantly in September with the gradual harvesting of crops, the cessation of irrigation, and the drop in temperature. The end of September was the period holding the lowest ET during the entire growing season when ET of farmland and bare land in the whole oasis area basically had no significant difference in spatial variation. 


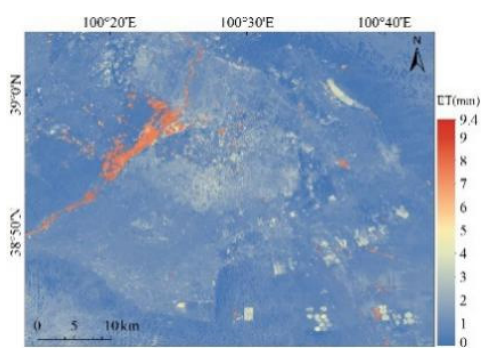

DOY124 (May 4)

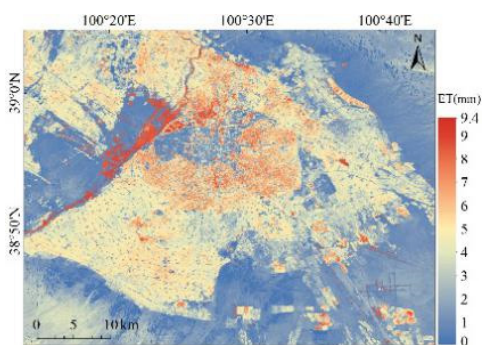

DOY154 (June 4)

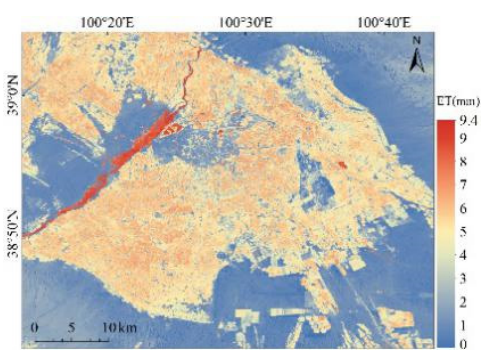

DOY184 (July 4)

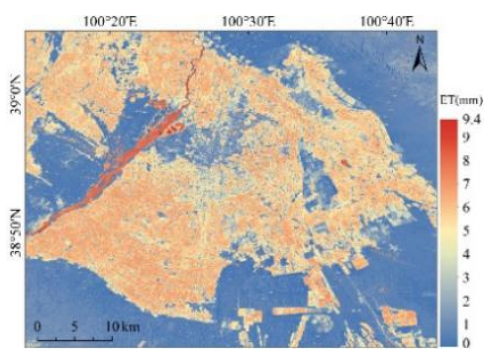

DOY214 (August 4)

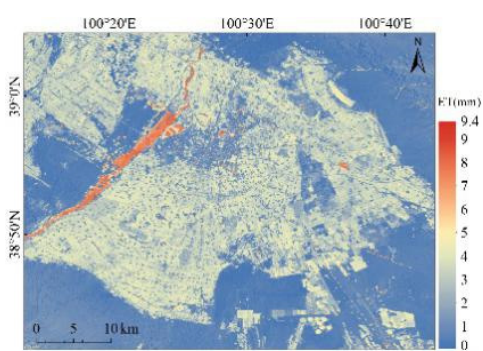

DOY247 (September 4)

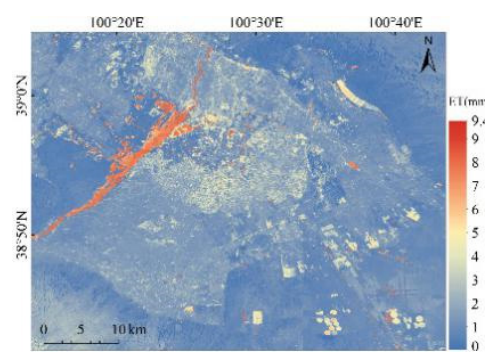

DOY125 (May 14)

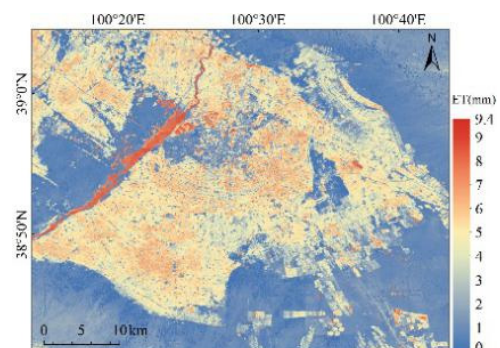

DOY155 (June 14)

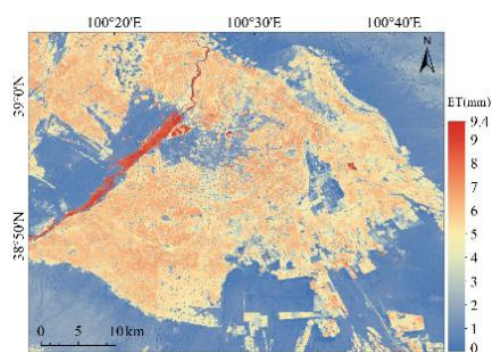

DOY185 (July 14)

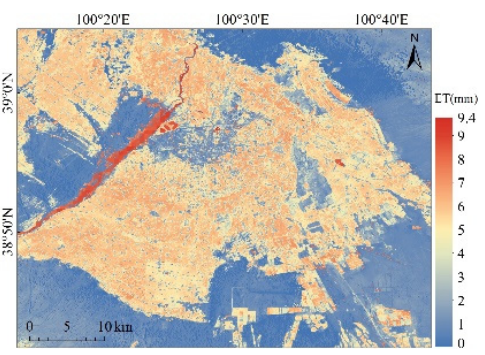

DOY215 (August 14)

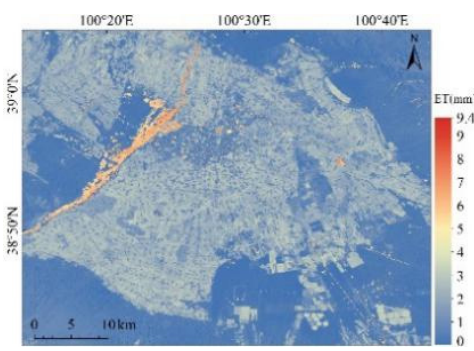

DOY248 (September 14)

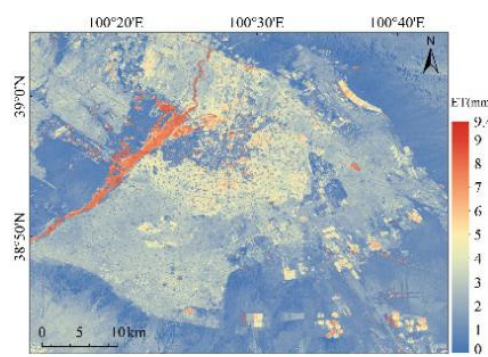

DOY126 (May 24)

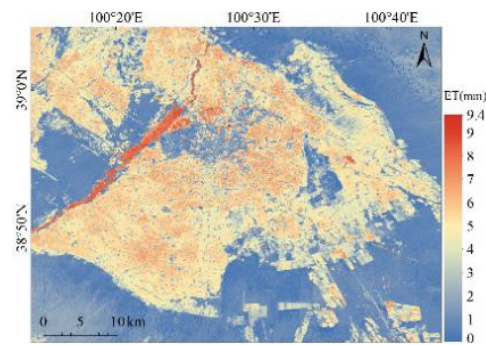

DOY156 (June 24)

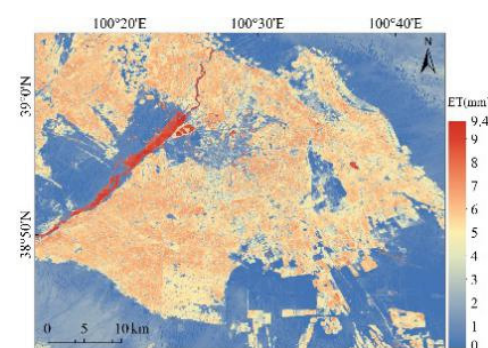

DOY186 (July 24)

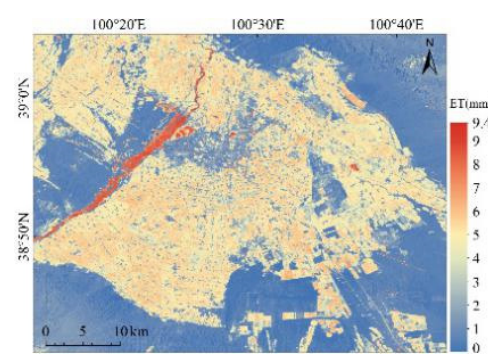

DOY216 (August 24)

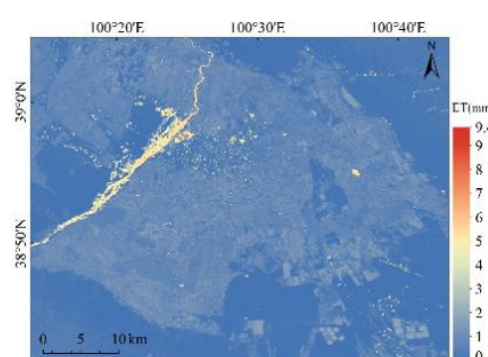

DOY249 (September 24)

Figure 6. Spatial variation of high spatiotemporal ET (evapotranspiration) during the growing season in Zhangye Oasis in 2015. 


\subsection{Dynamic Evolution of High Spatiotemporal ET}

Figure 7 displays the dynamic evolution of the averaged daily ET $\left(\mathrm{ET}_{\mathrm{avg}}\right)$ variation of various land cover types for the growing season. Overall, the $\mathrm{ET}_{\mathrm{avg}}$ variation of various land cover types showed a clear stratification phenomenon, in which the $\mathrm{ET}_{\mathrm{avg}}$ of water bodies has always remained the highest throughout the growing season while the dynamic change is not significant. The $\mathrm{ET}_{\mathrm{avg}}$ of the deciduous broadleaf forest is close to the evergreen needle leaf forest and both of them are slightly higher than that of croplands. As a vegetation type, the $\mathrm{ET}_{\text {avg }}$ of the deciduous broadleaf forest, evergreen needle leaf forest, croplands, and grasslands changed significantly over time, presenting a very similar consistent trend. The $\mathrm{ET}_{\mathrm{avg}}$ of urban and built-up is lower than that of grasslands but it is higher than that of barren or sparsely vegetated, the lowest $\mathrm{ET}_{\mathrm{avg}}$ of which is commonly observed in the growing season. During the whole growing season, $\mathrm{ET}_{\mathrm{avg}}$ of water bodies keep high level all the time. They begin to decline at the end of the growing season probably due to the decrease of air temperature. The rest of the land types showed a similar trend throughout the growing season. $\mathrm{ET}_{\mathrm{avg}}$ was relatively low at the beginning of the growing season in early May. It started to accelerate by the end of May and continued till mid-June and then the growth rate decreased. By the vigorous vegetation growth in July, $\mathrm{ET}_{\mathrm{avg}}$ gradually reached to the maximum and began to decline at the end of August. The $\mathrm{ET}_{\mathrm{avg}}$ in various land types decreased significantly and eventually dropped to the lowest level in September. The highest $\mathrm{ET}_{\mathrm{avg}}$ of various land types appeared in DOY200-220 (19 July-8 August).

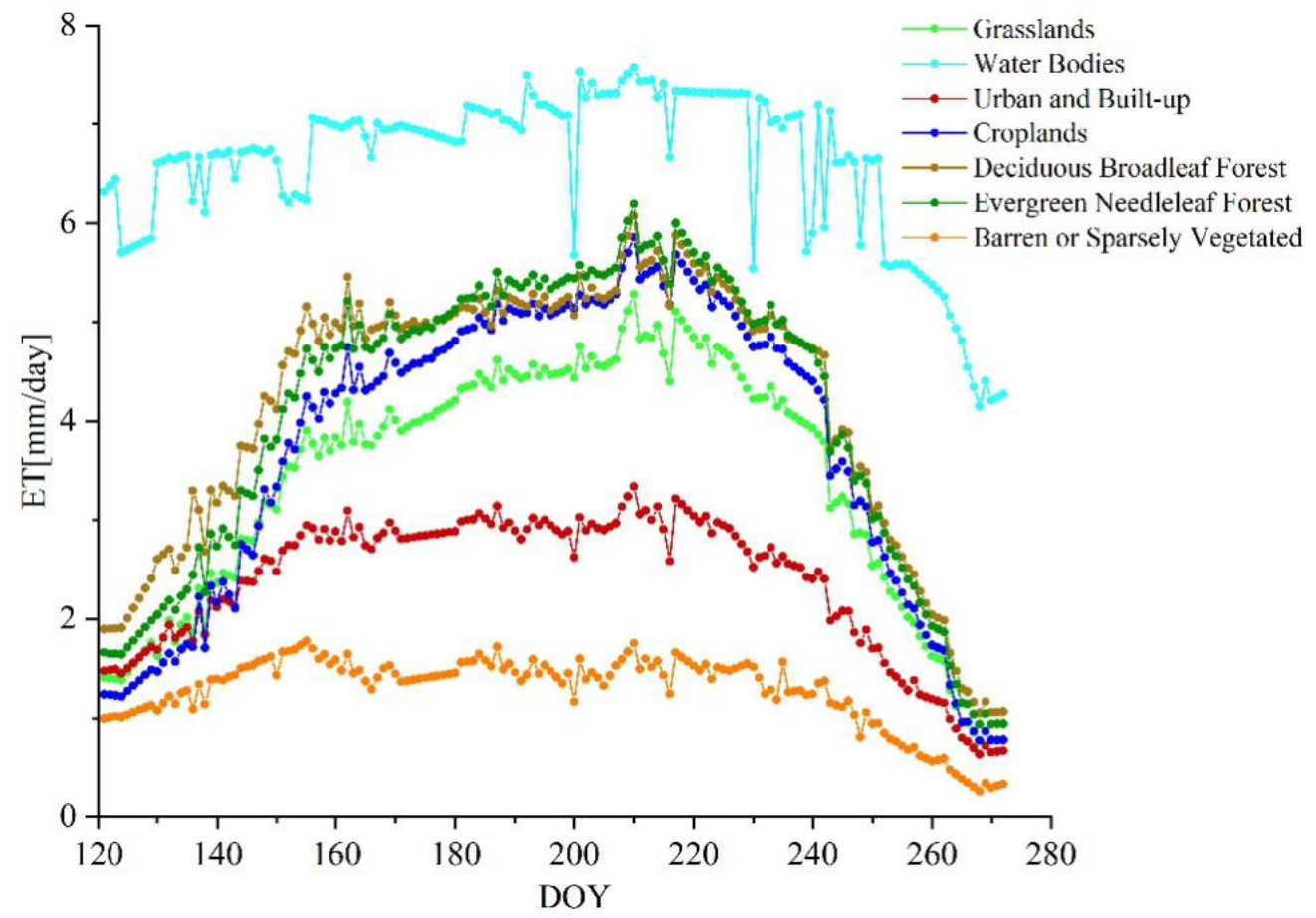

Figure 7. Dynamic evolution of the averaged daily ET variation of various land classes in the growing season.

\section{Discussion}

Evaluation of high spatiotemporal resolution ET (i.e., ET_WRF $\mathrm{HR}_{\mathrm{HR}}$ ) variation is mainly carried out from qualitative and quantitative aspects. The qualitative evaluation includes a comparison with available ET products and the reflection of ET_WRF $\mathrm{HR}_{\mathrm{HR}}$ on the refinement of ground features and the dynamic evolution process. However, no ET products with such a high spatial and temporal resolution covering the study area during the growing season have been released internationally, for which the MODIS ET product (MOD16A2, i.e., ET_MOD16) was adopted to compare with $\mathrm{ET}_{-} \mathrm{WRF}_{\mathrm{HR}}$ from the perspective of spatial 
distribution and details. Finally, the ET_WRF $\mathrm{HR}_{\mathrm{H}}$ was quantitatively verified based on ET observations.

\subsection{Comparison with MOD16 in Identifying Fine Features}

ET_MOD16 product from 28 July to 4 August of 2015 is selected as the vegetation growth is vigorous and ET is strong in this period. The ET_WRF $\mathrm{HR}_{\mathrm{H}}$ is accumulated for

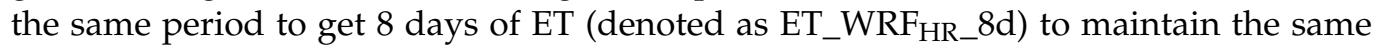
time scale with ET_MOD16. Five target areas (Figure 8) are designated for the comparison of refined manifestations. The ET_MOD16 and ET_WRF $F_{\text {HR_ }} 8 \mathrm{~d}$ present similar spatial patterns for the area considered. ET_MOD16 provides no ET values in the non-vegetation area while ET_WRF $F_{\text {HR_ }} 8 \mathrm{~d}$ reflects ET of various ground features with a higher spatial resolution.

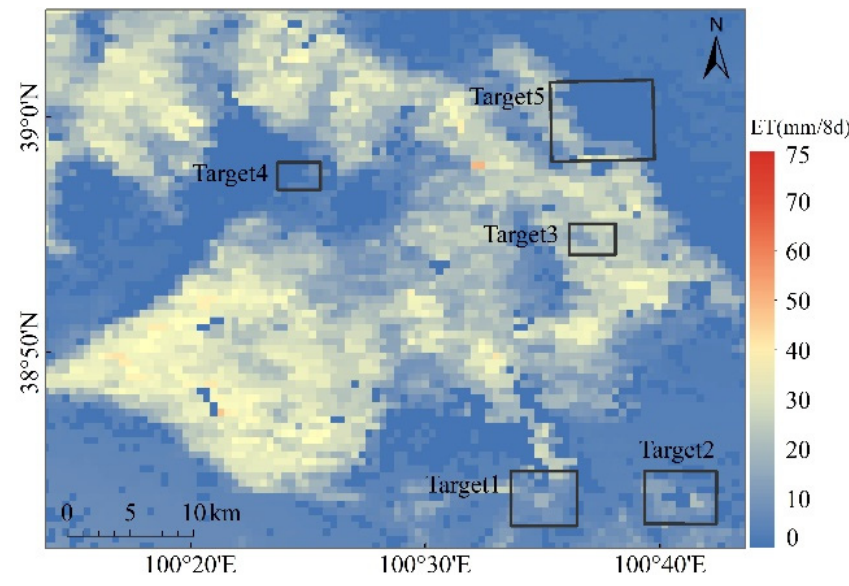

(a)

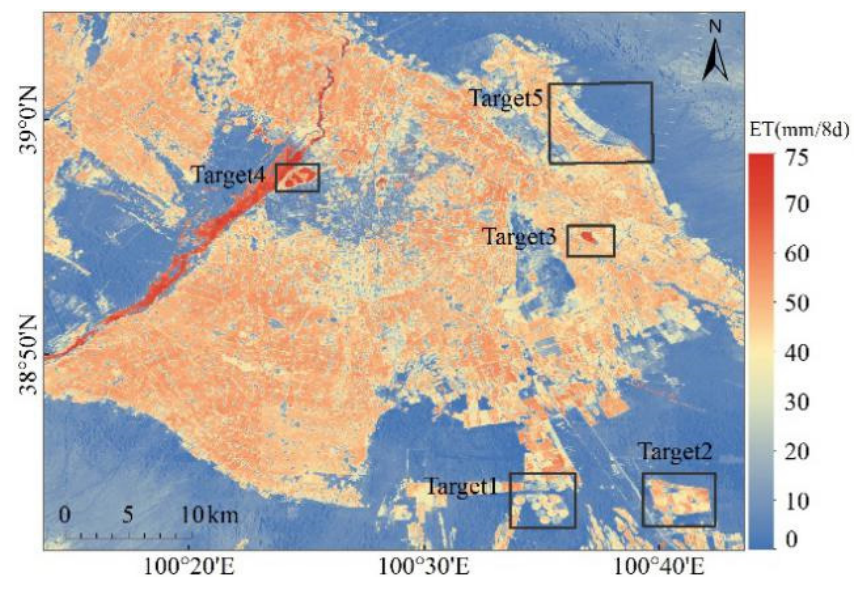

(b)

Figure 8. The spatial variation of (a) ET_MOD16 and (b) ET_WRFHR_8d with the target locations covering 28 July4 August 2015.

The finer scale comparison of the five targets is provided in Figure 9. Whether it is circular irrigation area (Target1 and Target2), lake (Target 3 and Target4) or fine features between lakes like the non-aqueous zone in the center of the lake (Target3), narrow zone between the lakes (Target4), or farmland planting structure, ET_MOD16 product cannot effectively identify them, while ET_WRF $\mathrm{HR}_{\mathrm{H}} 8 \mathrm{~d}$ product can better describe these fine features. The cross comparison clearly shows that ET_WRF HR_ $_{-} 8 \mathrm{~d}$ behave with a distinct advantage over ET_MOD16 in identifying the heterogeneity of the underlying surface.

\subsection{The Refined Embodiment of High Spatiotemporal ET}

The refinement embodiment of ET_WRF $\mathrm{WR}_{\mathrm{HR}}$ on a daily scale is elaborated from the aspects of spatial distribution and dynamic evolution in this section.

\subsubsection{ET Spatial Distribution of Target Geography Objects}

Figure 10 clearly shows that ET_WRF $\mathrm{HR}_{\mathrm{HR}}$ can better reflect the contour of circular irrigation area in Target2. It can also identify the non-vegetation area and different irrigation areas as well as the fine boundaries between the vegetation area and the non-vegetation area within the irrigation area (see the red line in Figure 10). 


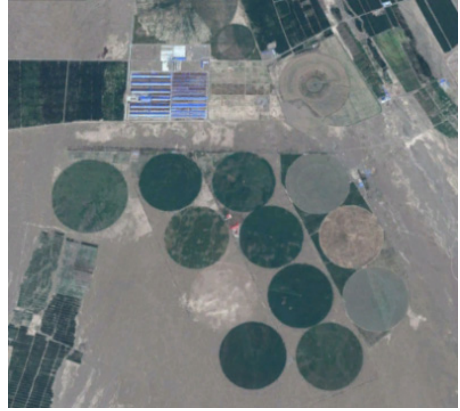

Target1 (August 4)

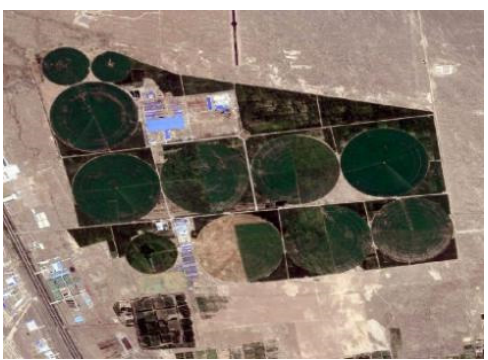

Target2 (August 4)

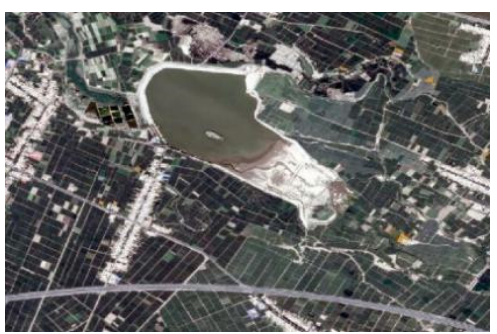

Target3 (August 4)

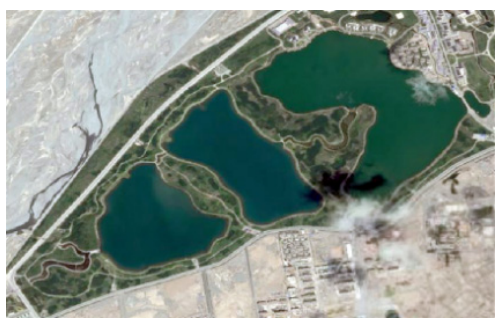

Target4 (August 13)

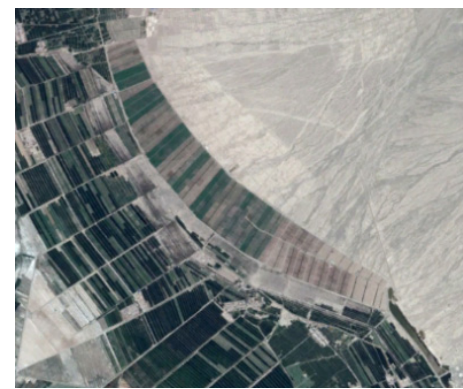

Target5 (August 4)

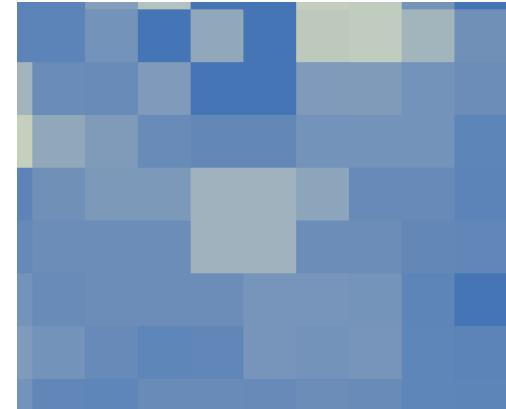

ET_MOD16

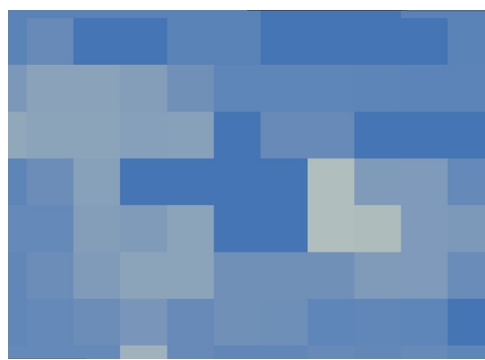

ET_MOD16

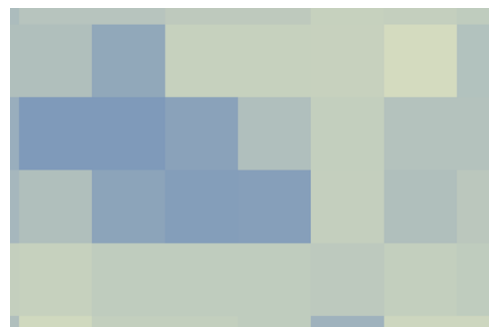

ET_MOD16

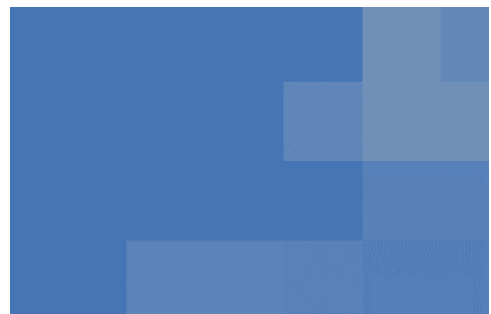

ET_MOD16

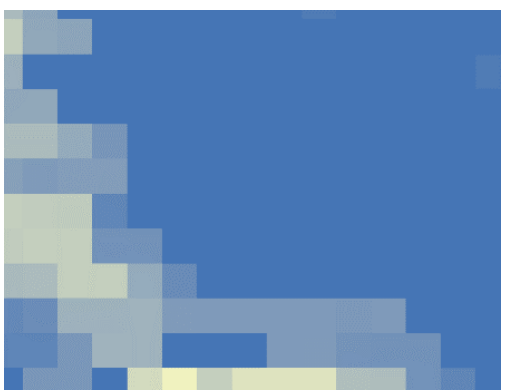

ET_MOD16

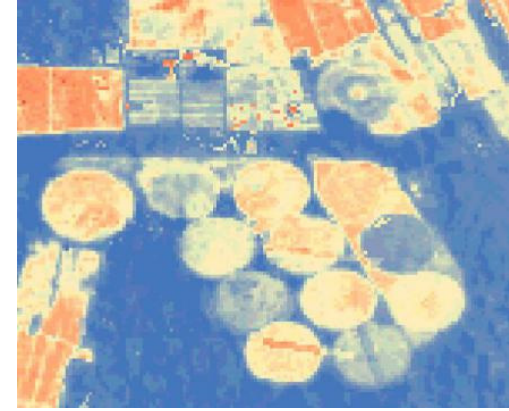

ET_WRFHR_8d

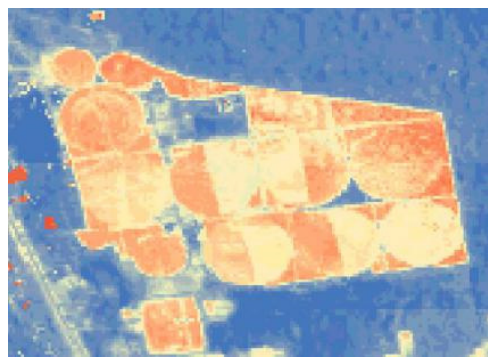

ET_WRFHR_8d

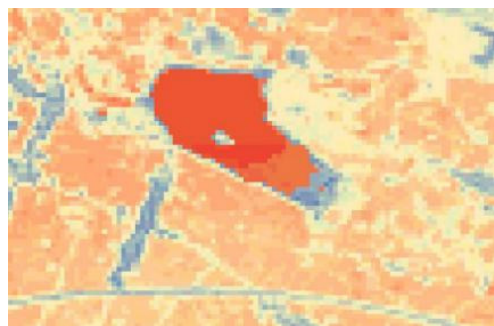

ET_WRFHR_8d

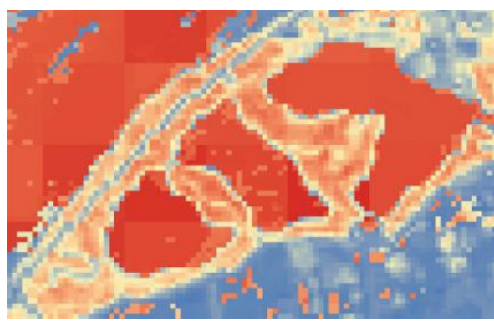

ET_WRFHR_8d

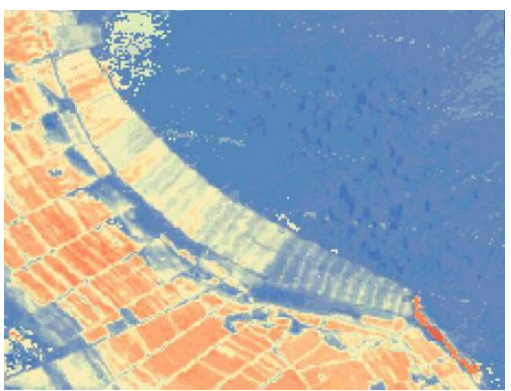

ET_WRFHR_8d

Figure 9. Finer scale comparison between ET_MOD16 and ET_WRF $\mathrm{HR}_{-} 8 \mathrm{~d}$ for the selected target areas. 

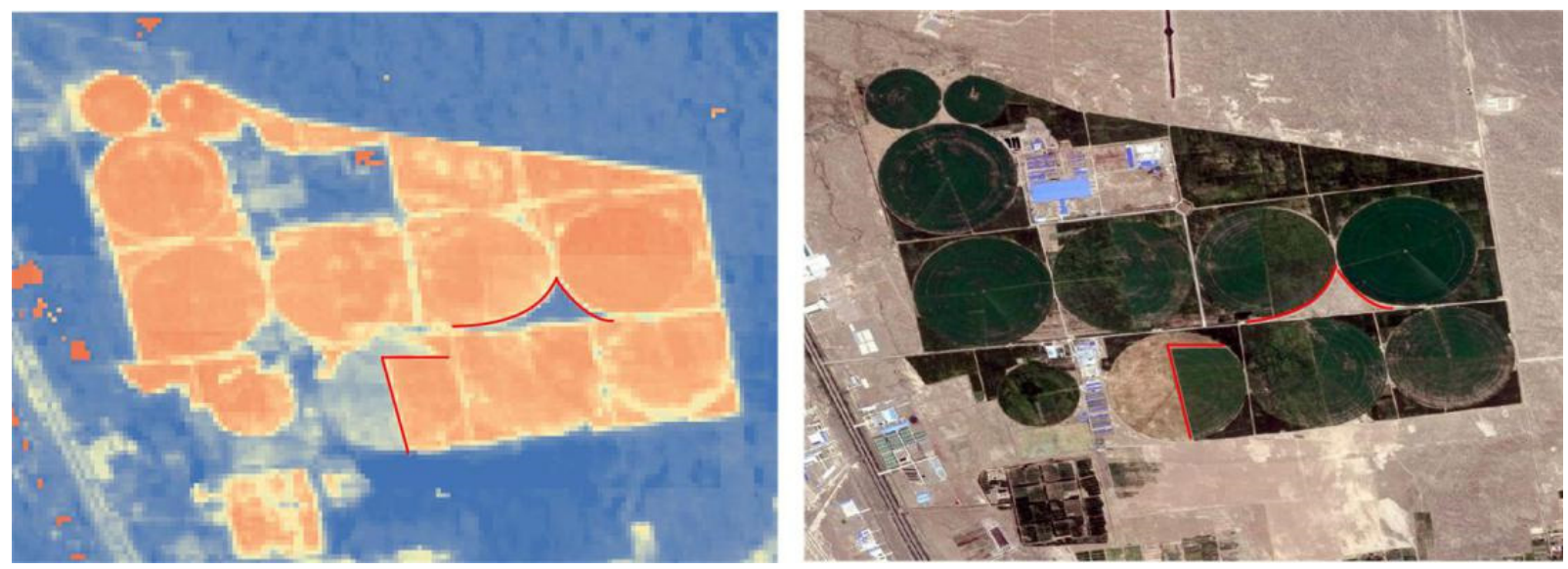

Figure 10. High-resolution ET distribution and finer visualization of Target2 on 4 August 2015.

Figure 11 shows that ET_WRF HR $_{\text {H }}$ presents a good performance in the identification of interphase distributed farmland (red box) and the farmland with dense planting structure (shown by the yellow line in Figure 11), and both Figures 10 and 11 indicate that ET_WRF $F_{\text {HR }}$ also represents a good reflection of the roads between the irrigation area and farmland, which generally reflects the refined presentation of $\mathrm{ET}_{-} \mathrm{WRF}_{\mathrm{HR}}$ on the spatial distribution difference of ET.
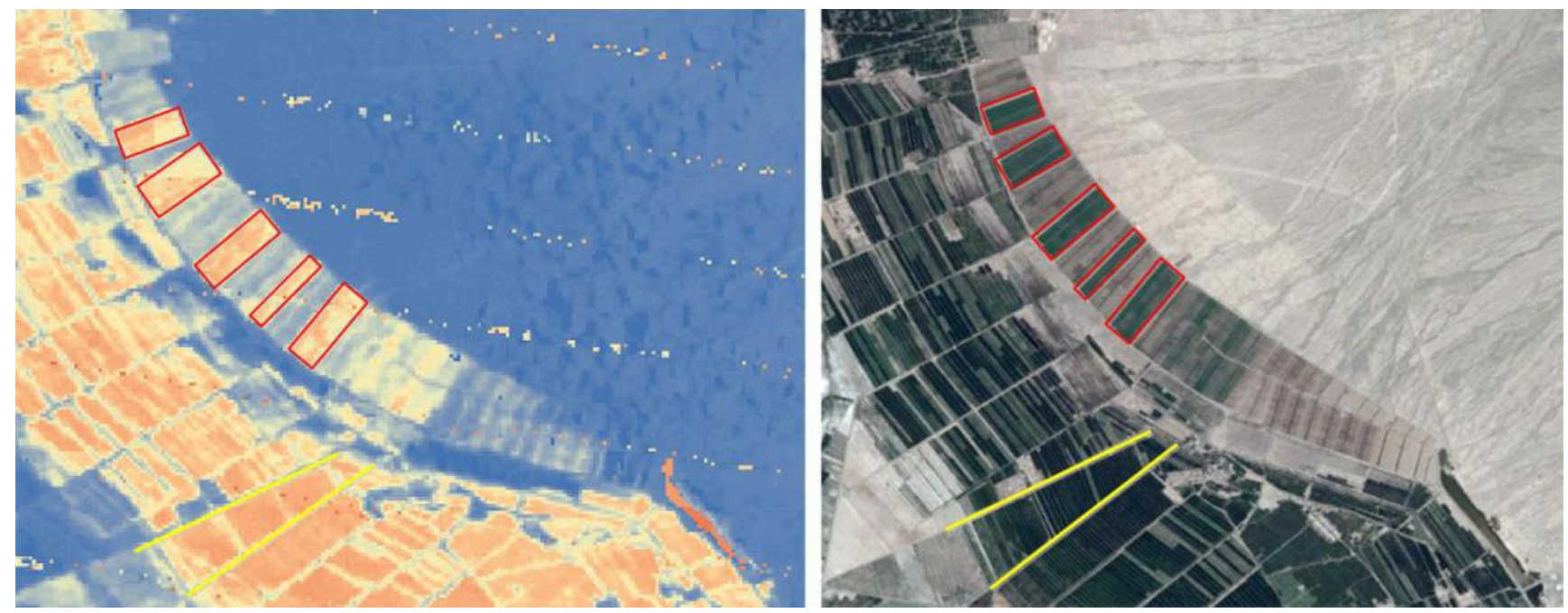

Figure 11. High-resolution ET distribution and finer visualization of Target5 on 4 August 2015.

\subsubsection{ET Dynamic Evolution of Target Geography Objects}

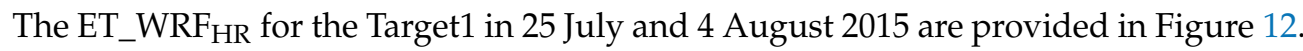
It shows that the ring-shaped features in the yellow circle on July 25 present a certain amount of ET and are successfully recognized by ET_WRF $F_{H R}$. Dynamic changes of the farmlands in the 25 July and 4 August images indicate that the vegetation coverage for some of the circular irrigation farmlands decreased significantly. Contrary, vegetation coverage in the red circle did not change and the ET_WRF $F_{H R}$ product reflects this phenomenon very well. There are red stripes in the ET_WRFFR product on 4 August. These are caused by the incomplete stripe removal of the Landsat7 ETM+ satellite image and they do not affect the analysis of the refinement of ET_WRF 

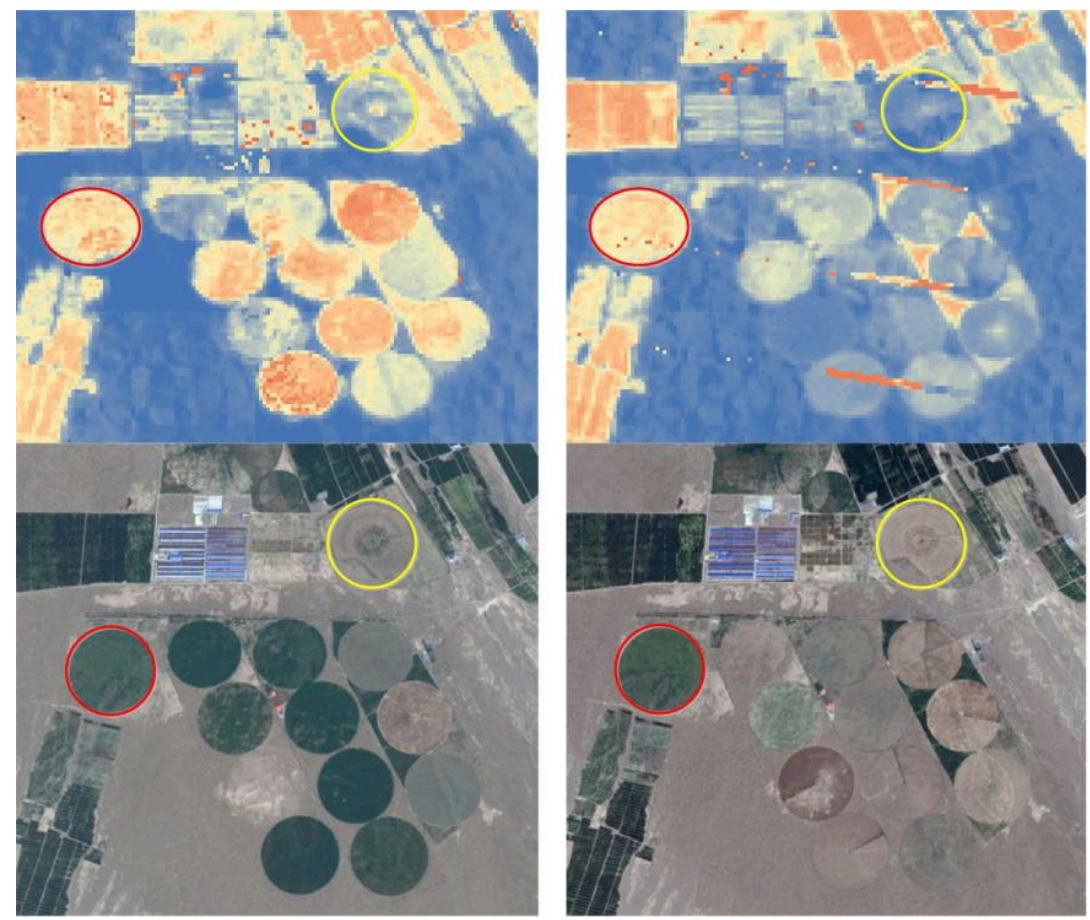

Figure 12. The dynamic evolution of ET_WRFHR and finer visualization of Target1 on 25 July (left) and 4 August (right) 2015.

\subsection{Quantitative Assessment of High Spatiotemporal ET}

4.3.1. Quantitative Comparison with ET_MOD16

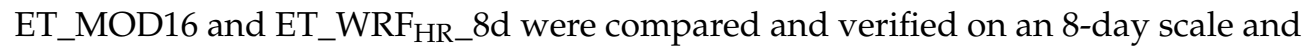
the same spatial scale (Figure 13). Results demonstrate that ET_WRF HR_8d has a very high correlation with the observations (ET_Obs_8d), the coefficient of determination $\left(\mathrm{R}^{2}\right)$ reaches 0.9426 , and the RMSE and BIAS are relatively low-respectively $5.58 \mathrm{~mm} / 8 \mathrm{~d}$ and $-0.63 \mathrm{~mm} / 8 \mathrm{~d}$-showing very good performance. In contrast, the correlation between ET_MOD16 and ET_Obs_8d is not so good as the former, whose $R^{2}$ is 0.6765 , and shows relatively high RMSE and BIAS, which are $11.37 \mathrm{~mm} / 8 \mathrm{~d}$ and $-6.57 \mathrm{~mm} / 8 \mathrm{~d}$, respectively. Higher BIAS indicates ET_MOD16 underestimates the ET overall, while the lower BIAS indicates that ET_WRFHR_8d comes closer to the observations than ET_MOD16.

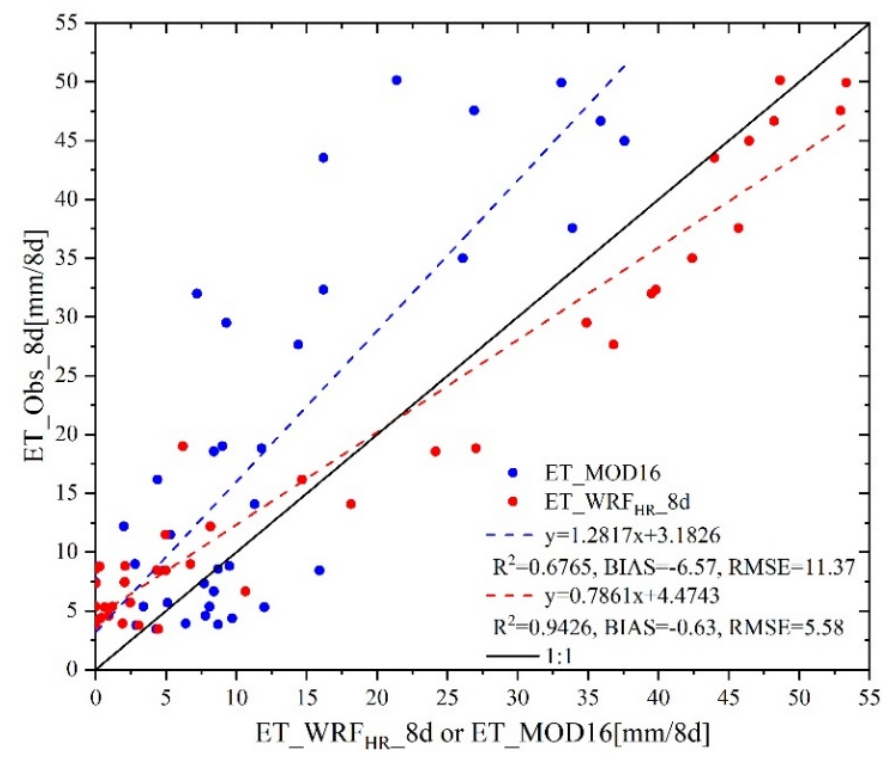

Figure 13. Scatter diagram of ET_MOD, ET_WRF HR_8d and ET_Obs_8d. 


\subsubsection{Quantitative Verification with Observations}

ET_WRF $_{\text {HR }}$ is compared with the ET observations (ET_Obs) in Figure 14. ET_WRF $F_{H R}$ and ET_Obs keep a consistent dynamic evolution trend throughout the growing season (Figure 14a) in each station. ET_WRF HR $_{\text {p }}$ provided relatively lower ET amounts compared to ET_Obs in Huazhaizi Desert Station, while the difference between the two is not significant. Figure 14b shows the scatter diagram of the ET_WRF HR $_{\text {R }}$ and ET_Obs for both sites. $R^{2}$ reached 0.9186 , while relatively small RMSE and BIAS amounts are obtained as $0.77 \mathrm{~mm}$ and $-0.08 \mathrm{~mm}$ respectively. The higher $\mathrm{R}^{2}$, as well as the smaller RMSE and BIAS, indicate that ET_WRF $\mathrm{HR}_{\mathrm{R}}$ provides pretty good ET estimation. However, some underestimations were found in high values, while some overestimations were observed in low values. According to the results in Figure 4 and the analysis of the principle of SEBS, the possible reason for this phenomenon is that the surface temperature obtained by fusion is underestimated in low vegetation coverage areas (such as Huazhaizi Station), which makes the difference between the surface and air temperature smaller, leading to lower sensible heat flux, so that the latent heat flux reaches too high; while in dense vegetation coverage areas (such as Daman Station), the situation may be just the opposite.

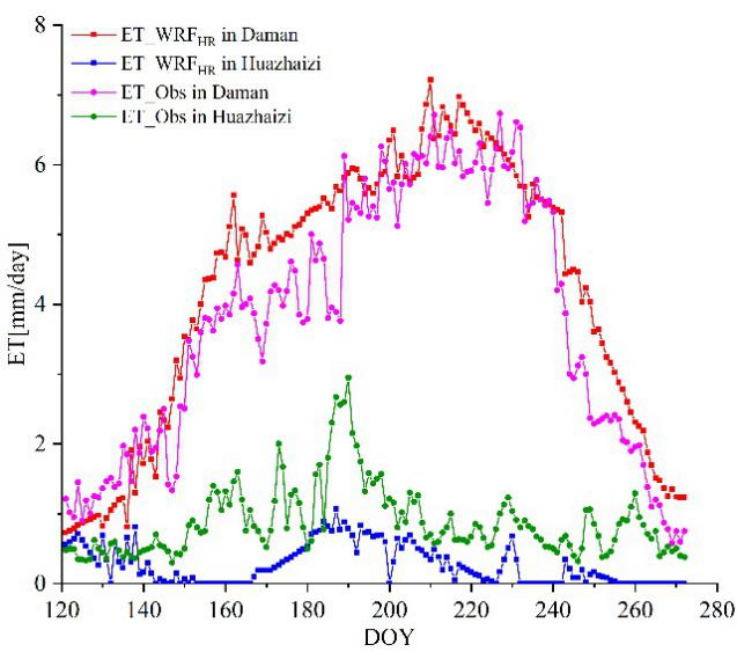

(a)

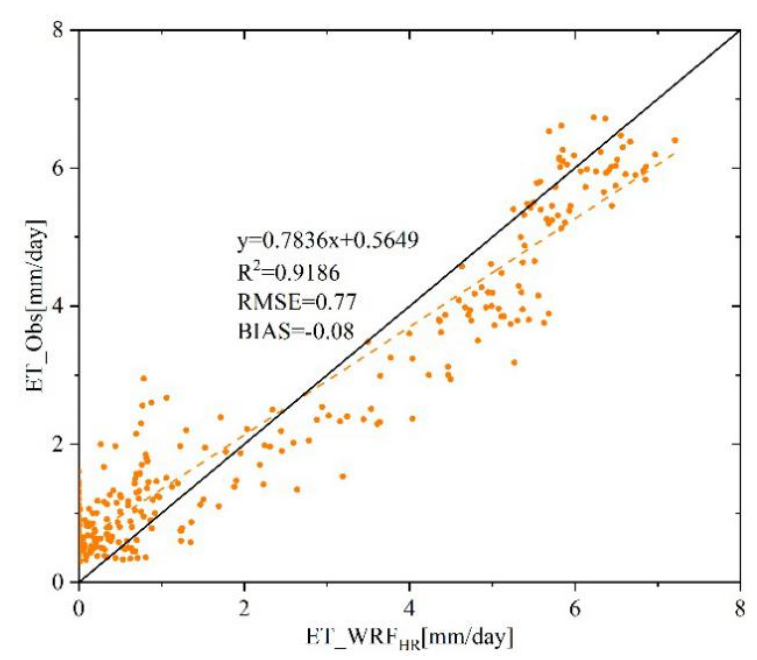

(b)

Figure 14. (a) Dynamic evolution comparison of ET_WRF $\mathrm{HR}_{\mathrm{H}}$ and ET_Obs in the growing season; (b) Scatter diagram of the ET_WRFHR and ET_Obs.

\section{Conclusions}

It is often difficult to provide continuous daily remote sensing surface temperature due to the limitation of the environment, weather, and the orbital period of the optical remote sensing satellite when estimating continuous daily ET with high spatiotemporal resolution. Improvement of the ESTARFM data fusion algorithm is proposed in this research by adding a normalization module to achieve high spatiotemporal resolution surface temperature for estimating the continuous daily high spatial resolution ET. The most important difference of this approach between previous studies on estimating high spatiotemporal resolution ET is the novel application of the WRF model surface skin temperature, which gives full play to the availability of model surface temperature data at any time and region, makes up for the shortcomings of the remote sensing data, and combines with the advantages of the high spatial resolution of remote sensing surface temperature.

Comparisons showed that the ET_WRF $\mathrm{HR}_{\mathrm{HR}}$ is better than the MODIS ET products in terms of temporal and spatial resolution. $\mathrm{ET}_{-} \mathrm{WRF}_{\mathrm{HR}}$ better reflects ET details for different land types and fine geographical objects, accurately captures the dynamic evolution of 
ET of various geographical objects and indicates a greater advantage in identifying the heterogeneity of the underlying surface.

Quantitative evaluation results showed that the ET_WRF $\mathrm{HR}_{\mathrm{HR}}$ and the ET observations not only kept a consistent dynamic evolution trend throughout the growing season but also hold very good correlation. High $\mathrm{R}^{2}$, as well as the small RMSE and BIAS, indicate that the ET_WRF HR $_{\text {R }}$ achieved good performance. The study area for this research is located in arid and semi-arid areas, soil water stress is relatively strong and the contribution of vegetation transpiration to ET is relatively large. The scheme of NDVI correction achieved good results under this climatic condition. Findings in this study are expected to guide future work to test and verify the applicability of the same scheme in larger research areas and other climatic conditions such as the humid climatic region.

Author Contributions: Conceptualization, D.W., T.Y., Y.L. and Y.Z. (Yulin Zhan); methodology, D.W., T.Y., Y.L., X.G. and M.M.; data curation and investigation, D.W., X.C., Y.Z. (Yin Zhang), Q.L., Y.Z. (Yulin Zhan) and F.M.; writing-original draft preparation, D.W.; writing-review and editing, D.W., Y.L., X.M., M.M., X.C., Y.Z. (Yin Zhang) and Y.Z. (Yulin Zhan); visualization, D.W., X.M., S.S. and X.C.; funding acquisition, T.Y., X.G. and Y.Z. (Yulin Zhan). All authors have read and agreed to the published version of the manuscript.

Funding: This research was funded by the Major Special Project of the National Development and Reform Commission of China (grant number Y930280A2F) and State Administration of Science, Technology and Industry for National Defense, PRC Pre-Research Project (grant number Y930060K8M, B0304), National Key R\&D Program of China (2019YFE0127300).

Institutional Review Board Statement: Not applicable.

Informed Consent Statement: Not applicable.

Data Availability Statement: Not applicable.

Conflicts of Interest: The authors declare no conflict of interest.

\section{References}

1. Feng, Y.; Jia, Y.; Cui, N.; Zhao, L.; Li, C.; Gong, D. Calibration of Hargreaves model for reference evapotranspiration estimation in Sichuan basin of southwest china. Agric. Water Manag. 2017, 181, 1-9. [CrossRef]

2. Carter, C.; Liang, S. Comprehensive evaluation of empirical algorithms for estimating land surface evapotranspiration. Agric. For. Meteorol. 2018, 256-257, 334-345. [CrossRef]

3. Wang, D.; Zhan, Y.; Yu, T.; Liu, Y.; Jin, X.; Ren, X.; Chen, X.; Liu, Q. Improving meteorological input for surface energy balance system utilizing mesoscale weather research and forecasting model for estimating daily actual evapotranspiration. Water 2019, 12, 9. [CrossRef]

4. Allan, R.G.; Pereira, L.; Raes, D.; Smith, M. Crop Evapotranspiration-Guidelines for Computing Crop Water Requirements-FAO Irrigation and Drainage Paper 56; FAO: Rome, Italy, 1998; Volume 56.

5. Li, F.; Lyons, T.J. Estimation of regional evapotranspiration through remote sensing. J. Appl. Meteorol. 1999, 38, 1644-1654. [CrossRef]

6. Sudheer, K.; Gosain, A.; Ramasastri, K. Estimating actual evapotranspiration from limited climatic data using neural computing technique. J. Irrig. Drain. Eng. 2003, 129, 214-218. [CrossRef]

7. Rahimikhoob, A. Estimation of evapotranspiration based on only air temperature data using artificial neural networks for a subtropical climate in Iran. Theor. Appl. Climatol. 2010, 101, 83-91. [CrossRef]

8. Wang, Z.; Wu, P.; Zhao, X.; Cao, X.; Gao, Y. Gann models for reference evapotranspiration estimation developed with weather data from different climatic regions. Theor. Appl. Clim. 2013, 116, 481-489. [CrossRef]

9. Elnmer, A.; Khadr, M.; Kanae, S.; Tawfik, A. Mapping daily and seasonally evapotranspiration using remote sensing techniques over the Nile delta. Agric. Water Manag. 2019, 213, 682-692. [CrossRef]

10. Ma, Y.; Song, M.; Ishikawa, H.; Yang, K.; Koike, T.; Jia, L.; Meneti, M.; Su, B. Estimation of the regional evaporative fraction over the Tibetan Plateau area by using landsat-7 ETM data and the field observations. J. Meteorol. Soc. Jpn. 2007, 85A, 295-309. [CrossRef]

11. Jiang, L.; Islam, S.; Bisht, G.; Venturini, V.; Carlson, T.; Guo, W.; Tarpley, D. Potential of satellite-based models for land surface evapotranspiration estimation. AGU Spring Meet. Abstr. 2005, 2005, H32B-03.

12. Samuel, A.; Girma, A.; Abraha, A.; Asfaha, T. Spatio-temporal variability of evapotranspiration and crop water requirement from space. J. Hydrol. 2018, 567, 732-742. [CrossRef] 
13. Akhtar, F.; Awan, U.; Tischbein, B.; Liaqat, U. Assessment of irrigation performance in large river basins under data scarce environment-A case of Kabul river basin, Afghanistan. Remote Sens. 2018, 10, 972. [CrossRef]

14. Sharma, V.; Kilic, A.; Irmak, S. Impact of scale/resolution on evapotranspiration from Landsat and Modis images. Water Resour. Res. 2016, 52, 1800-1819. [CrossRef]

15. Odongo, V.O.; van Oel, P.R.; van der Tol, C.; Su, Z. Impact of land use and land cover transitions and climate on evapotranspiration in the lake Naivasha Basin, Kenya. Sci. Total Environ. 2019, 682, 19-30. [CrossRef] [PubMed]

16. Li, Y.; Zhou, J.; Wang, H.; Li, D.; Jin, R.; Zhou, Y.; Zhou, Q. Integrating soil moisture retrieved from l-band microwave radiation into an energy balance model to improve evapotranspiration estimation on the irrigated oases of arid regions in northwest china. Agric. For. Meteorol. 2015, 214-215, 306-318. [CrossRef]

17. Su, Z. The surface energy balance system (SEBS) for estimation of turbulent heat fluxes. Hydrol. Earth Syst. Sci. 2002, 6, 85-100. [CrossRef]

18. Li, L.; Yu, Q.; Su, Z.; van der Tol, C. A simple method using climatic variables to estimate canopy temperature, sensible and latent heat fluxes in a winter wheat field on the north china plain. Hydrol. Process. 2009, 23, 665-674. [CrossRef]

19. Wu, X.; Zhou, J.; Wang, H.; Li, Y.; Zhong, B. Evaluation of irrigation water use efficiency using remote sensing in the middle reach of the Heihe river, in the semi-arid northwestern china. Hydrol. Process. 2015, 29, 2243-2257. [CrossRef]

20. Long, D.; Singh, V.P. A modified surface energy balance algorithm for land (m-sebal) based on a trapezoidal framework. Water Resour. Res. 2012, 48. [CrossRef]

21. Bastiaanssen, W.G.M.; Pelgrum, H.; Wang, J.; Ma, Y.; Moreno, J.F.; Roerink, G.J.; Wal, T.V.D. A remote sensing surface energy balance algorithm for land (SEBAL). Part 2: Validation. J. Hydrol. 1998, 212, 213-229. [CrossRef]

22. Jimenez-Munoz, J.-C.; Cristóbal Rosselló, J.; Sobrino, J.; Sòria Barres, G.; Ninyerola, M.; Pons, X. Revision of the single-channel algorithm for land surface temperature retrieval from Landsat thermal-infrared data. IEEE Trans. Geosci. Remote Sens. 2009, 47, 339-349. [CrossRef]

23. Wang, M.; Zhang, Z.; He, G.; Wang, G.; Long, T.; Peng, Y. An enhanced single-channel algorithm for retrieving land surface temperature from Landsat series data. J. Geophys. Res. Atmos. 2016, 121, 11712-11722. [CrossRef]

24. Zheng, X.; Li, Z.-L.; Nerry, F.; Zhang, X. A new thermal infrared channel configuration for accurate land surface temperature retrieval from satellite data. Remote Sens. Environ. 2019, 231, 111216. [CrossRef]

25. Wang, Y.-C.; Hu, B.K.H.; Myint, S.W.; Feng, C.-C.; Chow, W.T.L.; Passy, P.F. Patterns of land change and their potential impacts on land surface temperature change in Yangon, Myanmar. Sci. Total Environ. 2018, 643, 738-750. [CrossRef]

26. Sheng, Y.; Liu, X.; Yang, X.; Xin, Q.; Deng, C.; Li, X. Quantifying the spatial and temporal relationship between air and land surface temperatures of different land-cover types in southeastern china. Int. J. Remote Sens. 2017, 38, 1114-1136. [CrossRef]

27. Ogunbadewa, Y. Investigating availability of cloud free images with cloud masks in relation to satellite revisit frequency in the northwest of England. Contrib. Geophys. Geod. 2012, 42, 63-100.

28. Cammalleri, C.; Anderson, M.C.; Gao, F.; Hain, C.R.; Kustas, W.P. A data fusion approach for mapping daily evapotranspiration at field scale. Water Resour. Res. 2013, 49, 4672-4686. [CrossRef]

29. Semmens, K.A.; Anderson, M.C.; Kustas, W.P.; Gao, F.; Alfieri, J.G.; Mckee, L.; Prueger, J.H.; Hain, C.R.; Cammalleri, C.; Yang, Y. Monitoring daily evapotranspiration over two California vineyards using Landsat 8 in a multi-sensor data fusion approach. Remote Sens. Environ. 2015, 185, 155-170. [CrossRef]

30. Ma, Y.; Liu, S.; Song, L.; Xu, Z.; Liu, Y.; Xu, T.; Zhu, Z. Estimation of daily evapotranspiration and irrigation water efficiency at a landsat-like scale for an arid irrigation area using multi-source remote sensing data. Remote Sens. Environ. 2018, 216, 715-734. [CrossRef]

31. Yi, Z.; Zhao, H.; Jiang, Y.; Yan, H.; Yin, C.; Huang, Y.; Zhen, H. Daily evapotranspiration estimation at the field scale: Using the modified sebs model and hj-1 data in a desert-oasis area, northwestern china. Water 2018, 10, 640. [CrossRef]

32. Wang, T.; Tang, R.; Li, Z.-L.; Jiang, Y.; Liu, M.; Niu, L. An improved spatio-temporal adaptive data fusion algorithm for evapotranspiration mapping. Remote Sens. 2019, 11, 761. [CrossRef]

33. Allen, R.G.; Tasumi, M.; Morse, A.; Trezza, R.; Wright, J.L.; Bastiaanssen, W.; Kramber, W.; Lorite, I.; Robison, C.W. Satellite-based energy balance for mapping evapotranspiration with internalized calibration (metric)—Applications. J. Irrig. Drain. Eng. 2007, 133, 395-406. [CrossRef]

34. Mu, Q.; Heinsch, F.A.; Zhao, M.; Running, S.W. Development of a global evapotranspiration algorithm based on Modis and global meteorology data. Remote Sens. Environ. 2007, 111, 519-536. [CrossRef]

35. Jia, L.; Xi, G.; Liu, S.; Huang, C.; Yan, Y.; Liu, G. Regional estimation of daily to annual regional evapotranspiration with Modis data in the yellow river delta wetland. Hydrol. Earth Syst. Sci. 2009, 13, 1775-1787. [CrossRef]

36. Teixeira, A.H.d.C.; Bastiaanssen, W.G.M.; Ahmad, M.D.; Bos, M.G. Reviewing sebal input parameters for assessing evapotranspiration and water productivity for the low-middle São Francisco river basin, brazil: Part b: Application to the regional scale. Agric. For. Meteorol. 2009, 149, 477-490. [CrossRef]

37. Qiaozhen, M.U.; Zhao, M.; Steven, W. Improvements to a modis global terrestrial evapotranspiration algorithm. Remote Sens. Environ. 2011, 115, 1781-1800.

38. Wu, B.; Yan, N.; Xiong, J.; Bastiaanssen, W.G.M.; Zhu, W.; Stein, A. Validation of Etwatch using field measurements at diverse landscapes: A case study in Hai basin of China. J. Hydrol. 2012, 436-437, 67-80. [CrossRef] 
39. Xu, T.; Shaomin, L.; Xu, L.; Chen, Y.; Jia, Z.; Xu, Z.; Nielson, J. Temporal upscaling and reconstruction of thermal remotely sensed instantaneous evapotranspiration. Remote Sens. 2015, 7, 3400-3425. [CrossRef]

40. Cui, Y.; Jia, L. A modified gash model for estimating rainfall interception loss of forest using remote sensing observations at regional scale. Water 2014, 6, 993-1012. [CrossRef]

41. Jin, X.; Schaepman, M.; Clevers, J.G.P.W.; Su, B. Impact and consequences of evapotranspiration changes on water resources availability in the arid Zhangye basin, China. Int. J. Remote. Sens. 2009, 30, 3223-3238. [CrossRef]

42. Kovalskyy, V.; Henebry, G.M. Alternative methods to predict actual evapotranspiration illustrate the importance of accounting for phenology-Part 2: The event driven phenology model. Biogeosciences 2012, 9, 161-177. [CrossRef]

43. Wang, D.; Liu, Y.; Yu, T.; Zhang, Y.; Liu, Q.; Chen, X.; Zhan, Y. A method of using WRF-simulated surface temperature to estimate daily evapotranspiration. J. Appl. Meteorol. Climatol. 2020, 59, 901-914. [CrossRef]

44. Xu, T.; Guo, Z.; Liu, S.; He, X.; Meng, Y.; Xu, Z.; Xia, Y.; Xiao, J.; Zhang, Y.; Ma, Y.; et al. Evaluating different machine learning methods for upscaling evapotranspiration from flux towers to the regional scale. J. Geophys. Res. Atmos. 2018, 123, 8674-8690. [CrossRef]

45. Tan, M.; Zheng, L. Different irrigation water requirements of seed corn and field corn in the Heihe river basin. Water 2017, 9, 606 . [CrossRef]

46. Li, X.; Liu, S.; Xiao, Q.; Ma, M.; Jin, R.; Che, T.; Wang, W.; Hu, X.; Xu, Z.; Wen, J. A multiscale dataset for understanding complex eco-hydrological processes in a heterogeneous oasis system. Sci. Data 2017, 4, 170083. [CrossRef]

47. Chen, J.; Zhu, X.; Vogelmann, J.E.; Gao, F.; Jin, S. A simple and effective method for filling gaps in Landsat ETM+ SLC-off images. Remote Sens. Environ. 2011, 115, 1053-1064. [CrossRef]

48. Miao, J.; Zhou, X.; Huang, T.; Zhang, T.; Zhou, Z. A novel inpainting algorithm for recovering Landsat-7 ETM+ SLC-off images based on the low-rank approximate regularization method of dictionary learning with nonlocal and nonconvex models. IEEE Trans. Geosci. Remote Sens. 2019, 57, 6741-6754. [CrossRef]

49. Zhu, X.; Gao, F.; Liu, D.; Chen, J. A modified neighborhood similar pixel interpolator approach for removing thick clouds in Landsat images. IEEE Geosci. Remote Sens. Lett. 2012, 9, 521-525. [CrossRef]

50. Sobrino, J.A.; Jiménez-Muñoz, J.C.; Paolini, L. Land surface temperature retrieval from Landsat tm 5. Remote Sens. Environ. 2004, 90, 434-440. [CrossRef]

51. Zhu, X.; Chen, J.; Gao, F.; Chen, X.; Masek, J. An enhanced spatial and temporal adaptive reflectance fusion model for complex heterogeneous regions. Remote Sens. Environ. 2010, 114, 2610-2623. [CrossRef]

52. Rao, Y.; Zhu, X.; Chen, J.; Wang, J. An improved method for producing high spatial-resolution NDVI time series datasets with multi-temporal Modis NDVI data and Landsat TM/ETM+ images. Remote Sens. 2015, 7, 7865-7891. [CrossRef]

53. Feng, G.; Masek, J.; Schwaller, M.; Hall, F. On the blending of the Landsat and Modis surface reflectance: Predicting daily Landsat surface reflectance. IEEE Trans. Geosci. Remote Sens. 2006, 44, 2207-2218. [CrossRef]

54. Paredes, P.; Martins, D.S.; Pereira, L.S.; Cadima, J.; Pires, C. Accuracy of daily estimation of grass reference evapotranspiration using era-interim reanalysis products with assessment of alternative bias correction schemes. Agric. Water Manag. 2018, 210, 340-353. [CrossRef]

55. Sohrabinia, M.; Rack, W.; Zawar-Reza, P. Analysis of modis lst compared with wrf model and in situ data over the Waimakariri river basin, Canterbury, New Zealand. Remote Sens. 2012, 4, 3501-3527. [CrossRef]

56. Mahrt, L.; Ek, M. The influence of atmospheric stability on potential evaporation. J. Appl. Meteorol. 1984, 23, 222-234. [CrossRef]

57. Pielke, R.A.; Mahmood, R.; McAlpine, C. Land's complex role in climate change. Phys. Today 2016, 69, 40-46. [CrossRef]

58. Yang, Z.-L. Modeling land surface processes in short-term weather and climate studies. In Observation, Theory and Modeling of Atmospheric Variability; WORLD SCIENTIFIC: Hackensack, NJ, USA, 2004; Volume 3, pp. 288-313. 